\title{
استخدام العداد الصيني في تتمية المهارات الاجتماعية لأطفال الروضة
}

إعداد :

الباحثة / إيمان محمد أحمد عبد الرحمن '
د. عزة عبد المنعم رضوان

مدرس بقسم العلوم النفسية

كلية التربية للطفولة المبكرة

جامعة القاهرة
أ.د.بطرس حافظ بطرس

أستاذ الصحة النفسية وعميد كلية التربية

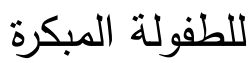

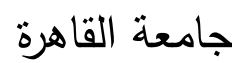

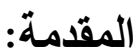

يعد الاهتمام بالأطفال اهتماماً بمستقبل الأمة كلها، لأن إعدادهم وتربيتهم يعد أعدادًا لمواجهة

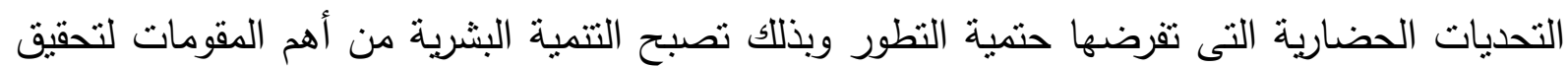

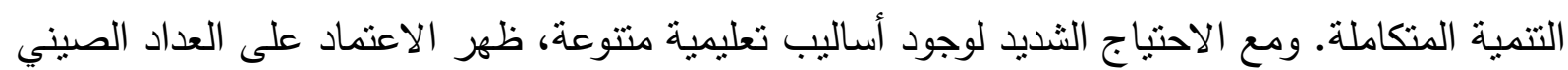

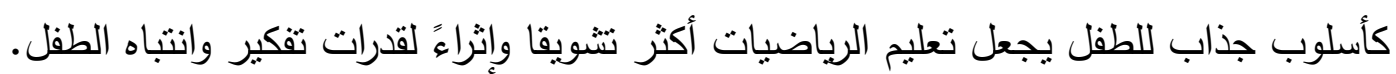

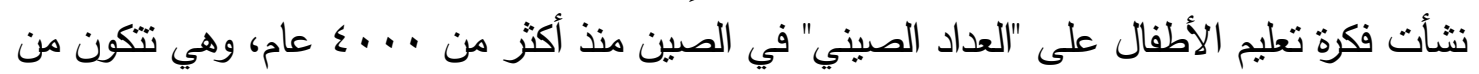

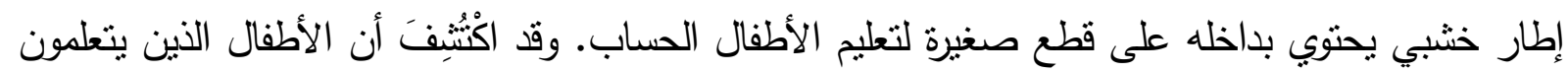

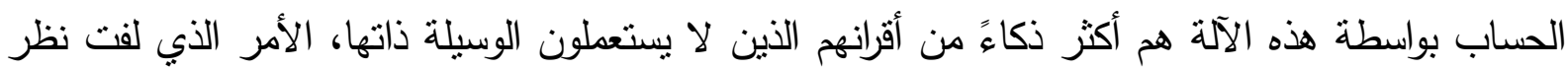

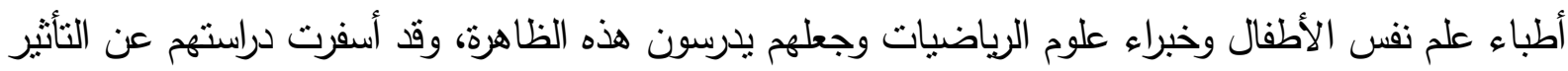

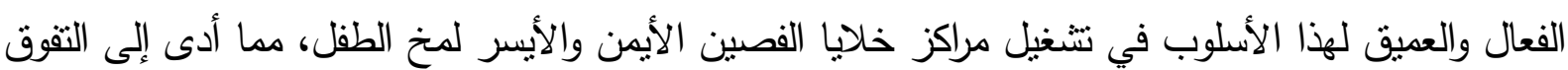

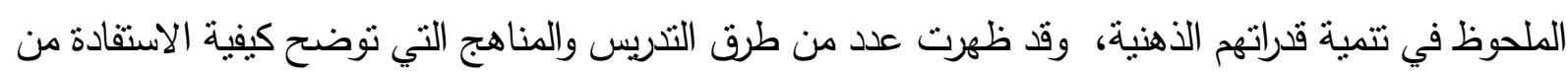
هذه الاداة (Chung, 2016: 3 (C)

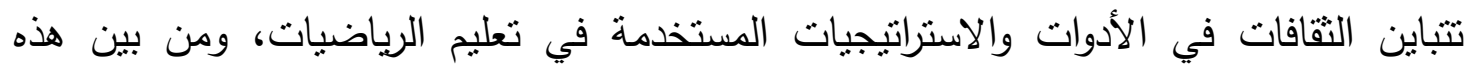

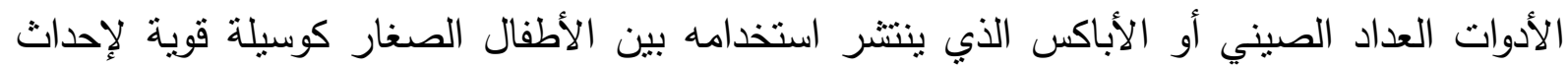

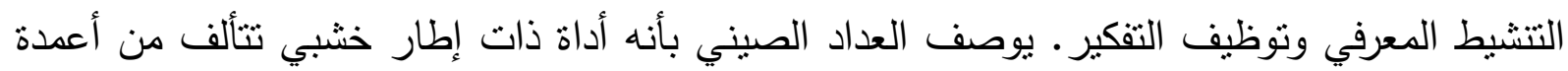


أو دعامات ذات خرزات متحركة ويتم استخدامها في أداء العمليات الحسابية الأساسية مثل الجمع والطرح .(Uttal, Scudder, \& Deloache, 2016: 37) ميز الله الانسان بالعديد من المميزات التى تمكنه من عمارة الارض واحيائها ،ومنها انه كائن

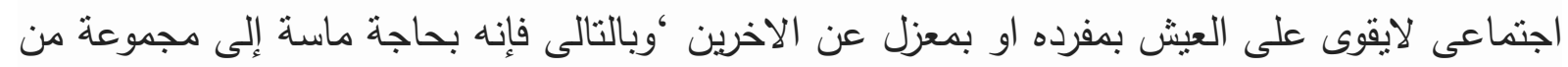

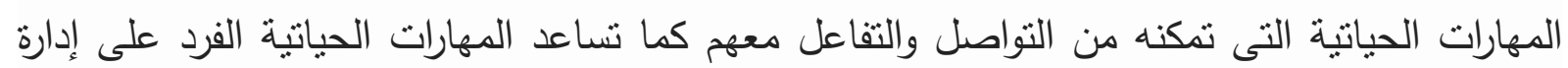

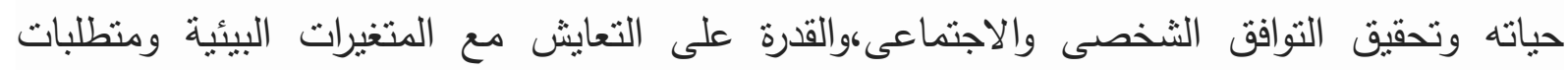

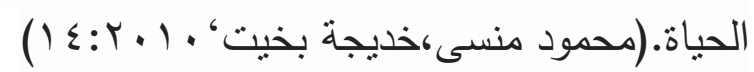
تعتبر المهارات الاجتماعية نموذجاً للسلوك الاجتماعي، واتهية وكيفية التعبير الاجتماعي اللفظي

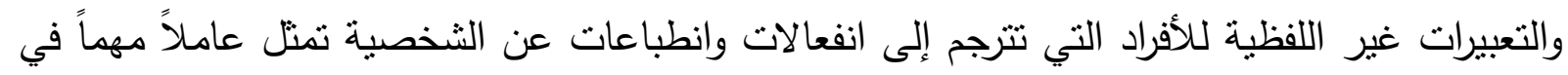

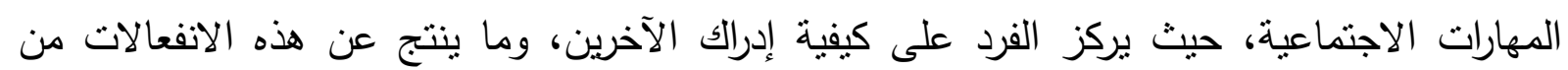

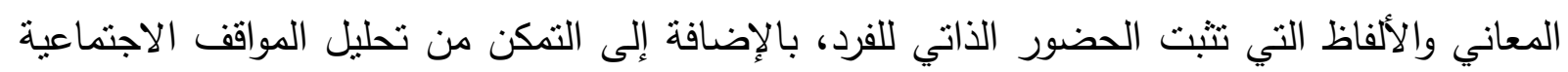

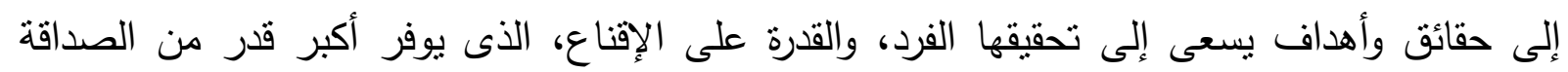
والحب بين الآخرين.

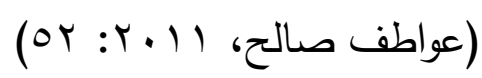

وتتمتل أهمية المهارات الاجتماعية باعتبارها تمثل مع القدرات العقلية قطبي الكفاءة والفعالية في باعي

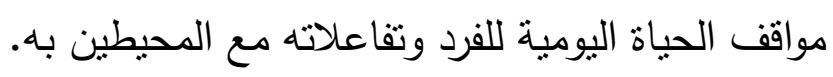

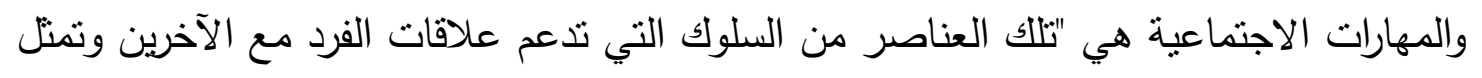
(Vaughn \& Morris, 2003: 232)

$$
\text { أهية بالغة كي يحافظ الفرد على التفاعل الإيجابي مع الآخرين". }
$$

والطفل بحاجة ماسة إلى تتمية المهارات الاجتماعية التى تكفل له حياة سليمة فويمكن اكساب

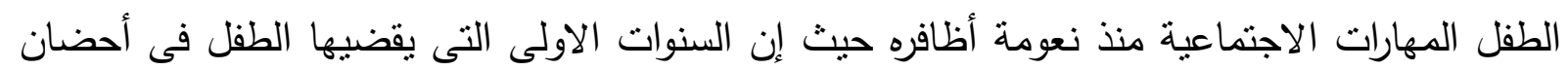

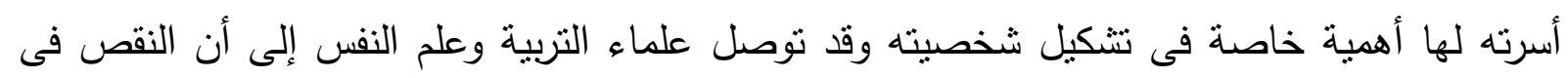

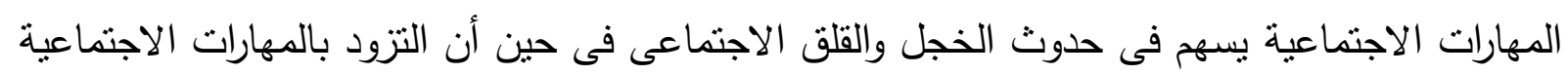

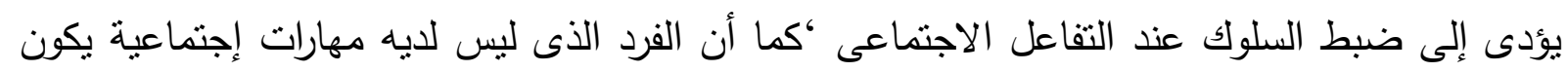

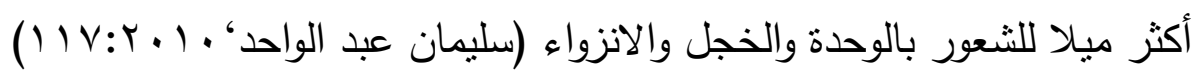

مشكلة الاراسة مئة

إن الأطفال في سن ما قبل المدرسة تكون خلايا عقلهم قابله للنتكل حسب المثيرات والمحفزات

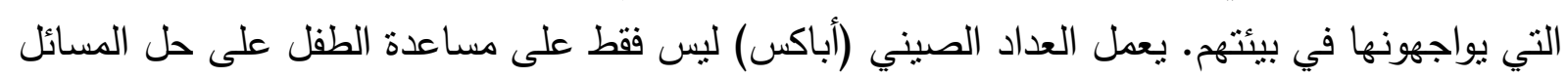

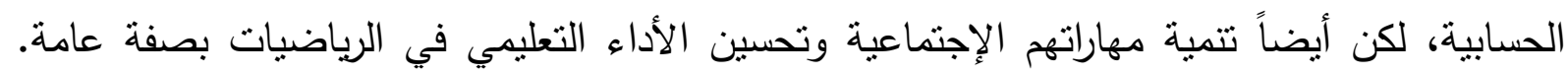

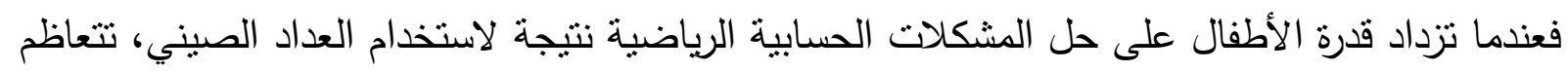

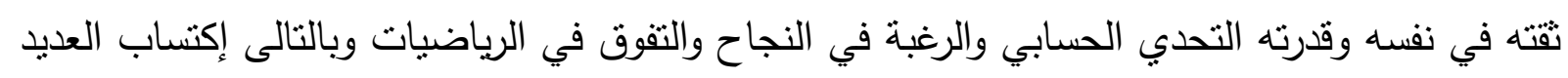

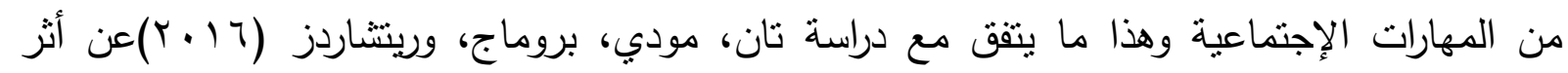

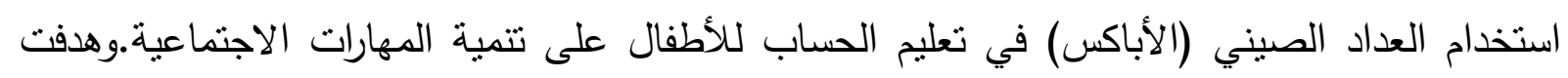


الدراسة إلى فحص تأثير التدريب الجماعي لأطفال الروضة على الأباكس في تعلم الرياضيات على تتمية

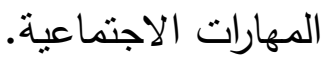

ومن هنا فقد نولد للباحثة الإحساس والثعور بأهمية إجراء الدراسة للتعرف على فاعلية العداد

الصيني في تتمية المهارات الإجتماعية لما يترتب عليها من آثار هامة في نمو الطاحفة الطفل فى جميع

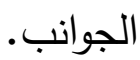

\section{وفي ضوع ما سبق بمكن تحدبـ مشكنة الدراسة في التساؤل الآتي:}

ما فاعلية العداد الصيني في تتمية المهارات الإجتماعية للأطفال الصغار في مرحلة الروضية الصنية

أهمبة الدراسة:

تكمن أهمية الدراسة في جانبين:

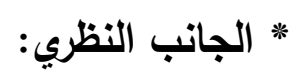

1- عرض تأصيل نظرى و دراسات سابقة عن فاعلية العداد الصيني في تتمية المهارات الإجتماعية

$$
\text { لبأطفال في مرحلة الروضة. }
$$

r- ندرة البحوث والدراسات (في حدود علم الباحثة) التي تتاولت فاعلية استخدام العداد الصيني في مجال ت تمية المهارات الإجنماعية.

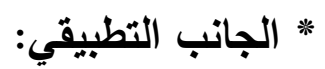

1- تقديم نموذج تعليمي قائم على استخدام العداد الصيني بما يشمل من طرق وأساليب تعلم متتوعه الإبه

$$
\text { بلإكساب الأطفال المهارات الإجتماعية. }
$$

r- تقديم بعض التوصيات والمقترحات في ضوء ما سوف تقدمه الدراسة الحالية.

الأهداف:

تهذف هذه الاراسة إلى:

1- بحث فاعلية استخدام العداد الصيني في تتمية الذكاء المهارات الإجتماعية للأطفال في مرحلة

$$
\text { الروضة. }
$$

ץ- بحث انعكاس استخدام العداد الصيني في تتمية المهارات الإجتماعية للأطفال على انجازهم في

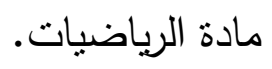

مصطلحات الإراســة:

أولاً: العداد الصيني:

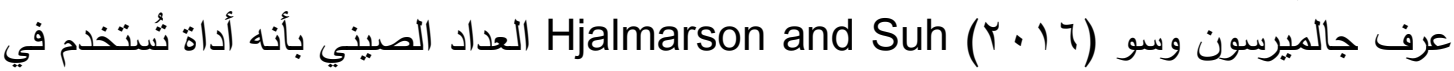

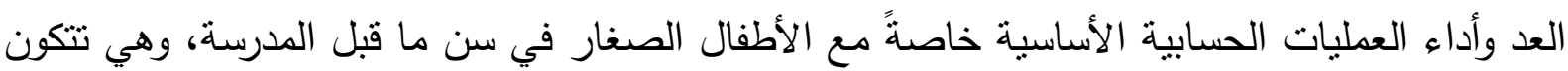

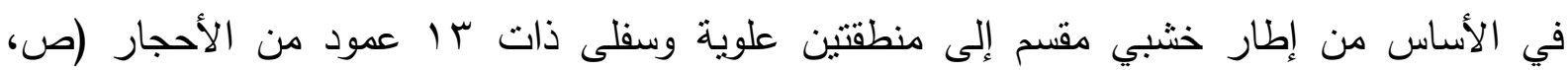


ثانباً: المهارات الإجتماعية:

هى مجموعة من الخبرات والأنشطة التى يكتسبها طفل الروضة ويكررها ويتدرب بطريقة منظمة الإنة

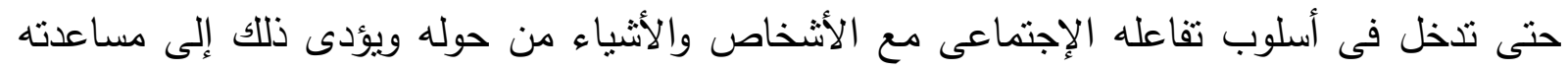

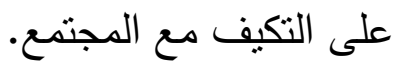

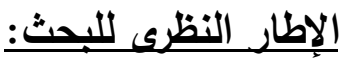
أولا: العداد الصيني: العيطي:

يُعد العداد الصيني هو أول وسيلة مساعدة خارجية لإجراء العمليات الرياضية والحسابية عرفها

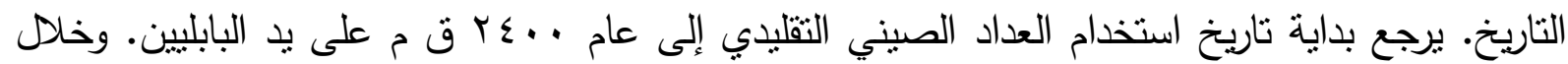

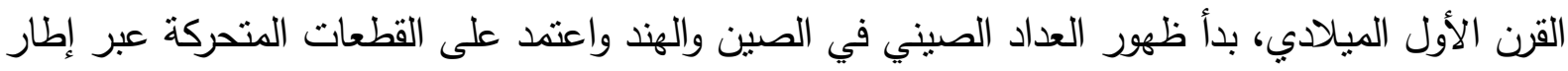

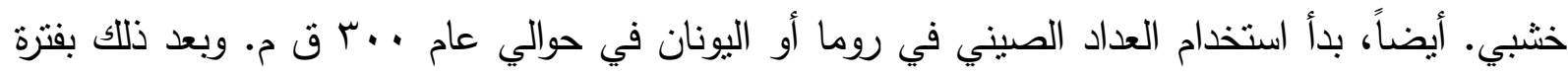

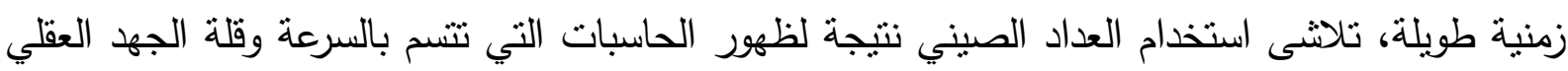

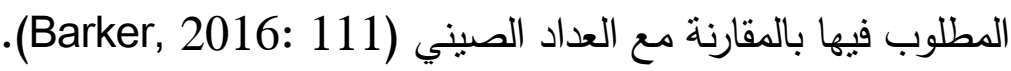
العداد الصيني هو نوع من الحاسبات التقليدية التي طالما استخدمت في دول الصئ الصين وكوريا واليابان

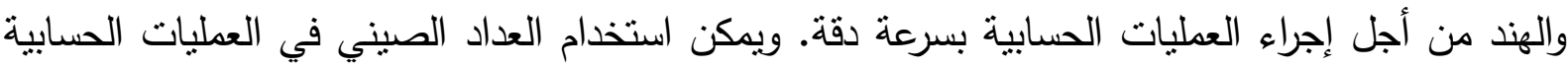

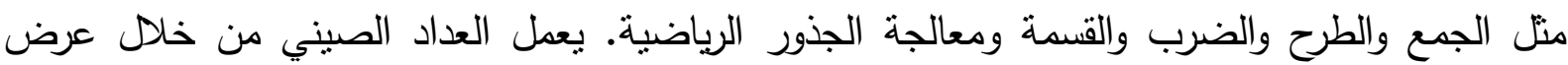

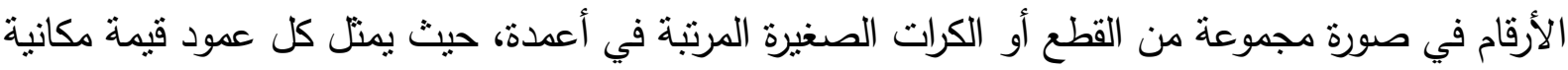
تنزايد من اليمين إلى اليسار (Li, Chen, \& Huang, 2016:9).

أهمية العداد الصيني للأطفال الصنفار:

يمتل العداد الصيني استراتيجة مميزة يمكن استخدامها في حل المشكلات الرياضية والحسايية بسرعة ودقة

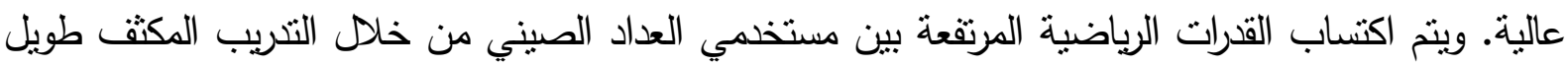

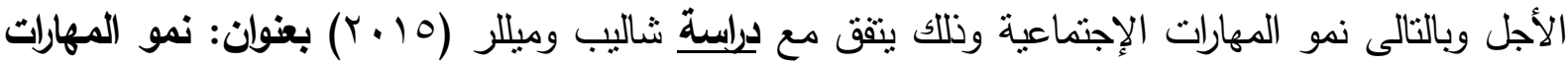

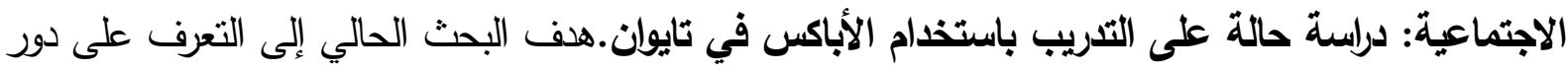

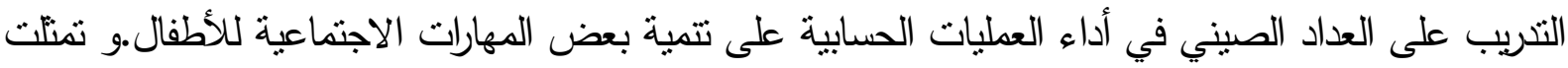

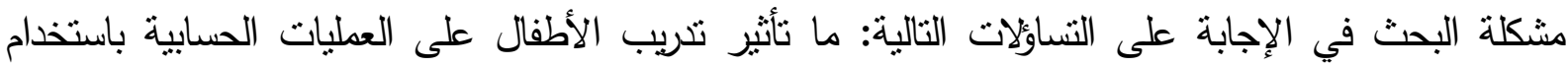

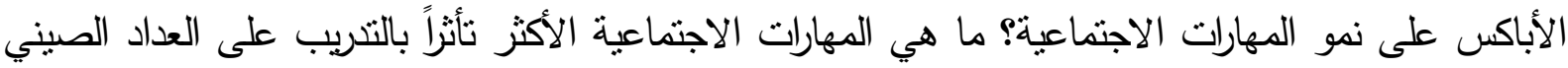

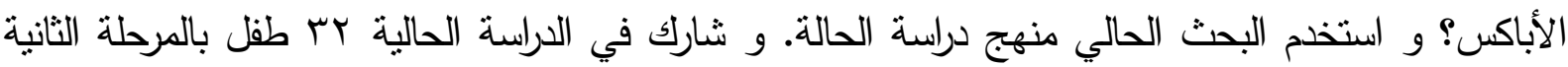

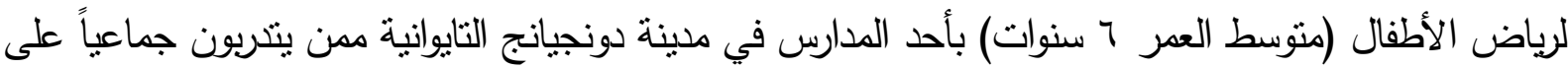

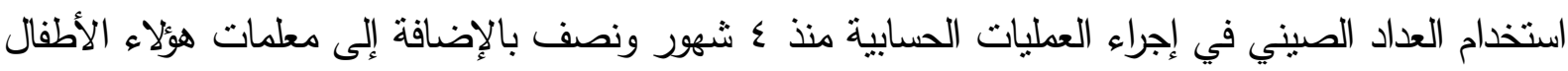

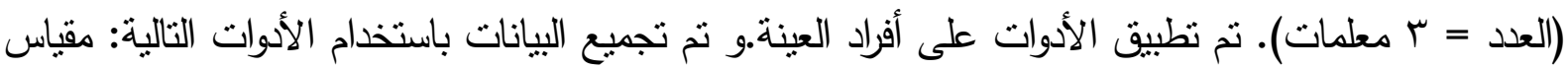

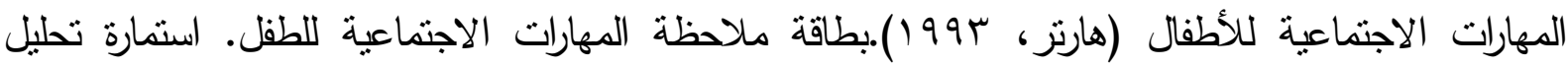

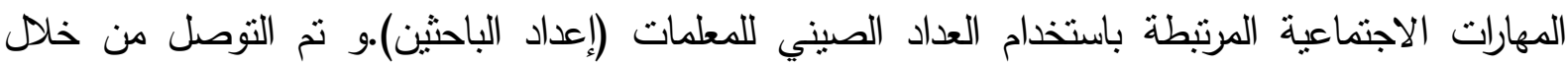

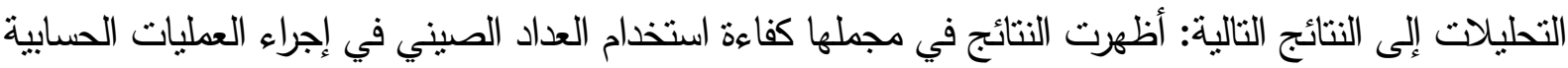

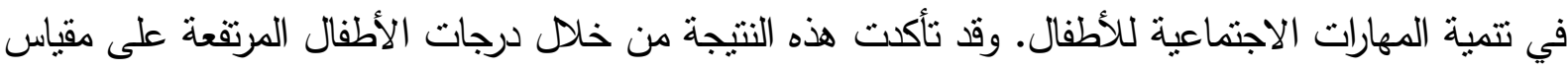

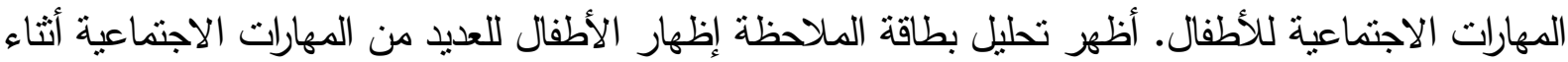


تعلم إجراء العطليات الحسابية باستخدام العداد الصيني. أثنارت المعلمات إلى أن الدهارات الاجتماعية الأكثر

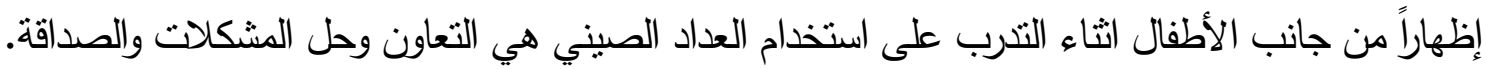
وصف (Fan, Dai \& Liu, 2017: 24) جوانب أهمية العداد الصيني للأطفال الصغار كما يلي:

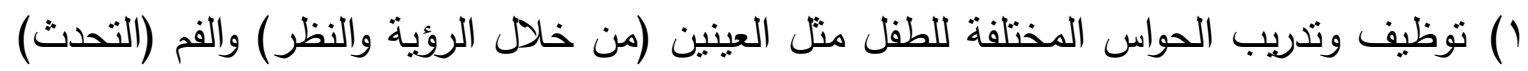
و اليدين (تحريك قطع العداد) والعقل (التفكير في العمليات الحسابية). r القدرة على عد الأرقام والكميات بسرعة وكفاءة عالية.

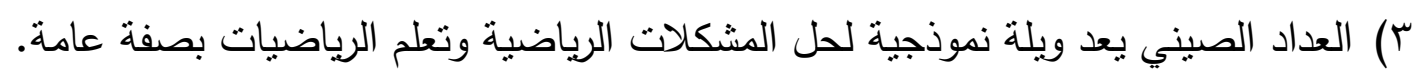

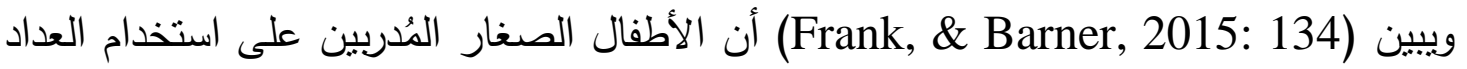

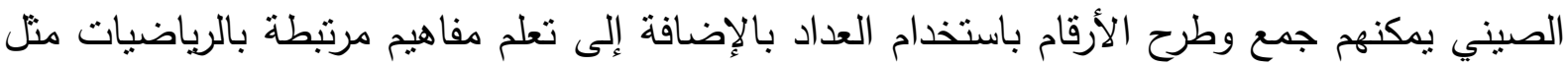

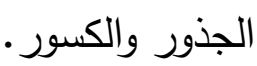

\section{خصائص العداد الصيني:}

يبين (Krampner, 2014:11) أن الخصائص الثابتة للعداد الصيني تضم كل من: - - - غرس عادات الملاحظة الدقيقة المتأنية في الأطفال. - - - غرس عادات الذاكرة الجيدة واسترجاع البيانات بأعلى مستويات الكفاءة وأقل قدر من الطاقة بين الأطفال. - - مان. - - غرس عادة استخدام العديد من المهارات في نفس الوقت بأعلى مستويات الكفاءة.

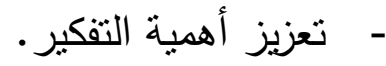
توسيع نطاق القوى العقلية للأطفال مثل التخيل والإبداع وتتمية المهارات الإنهات الإنماعية.

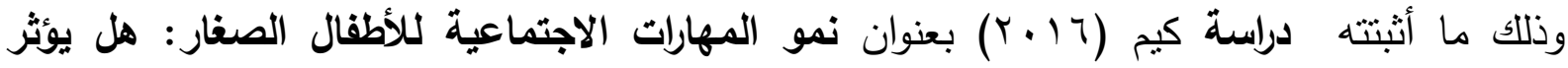

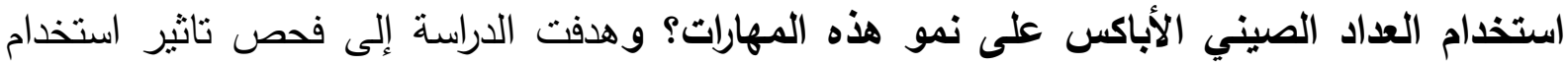

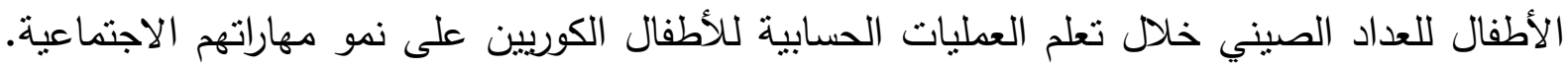

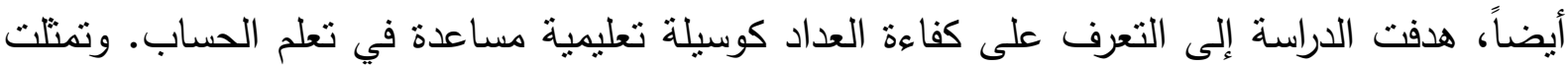

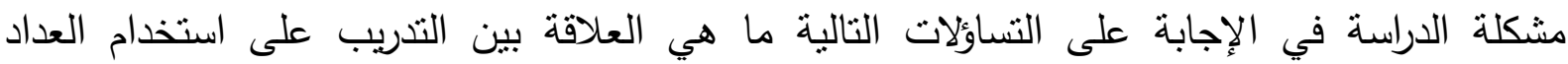

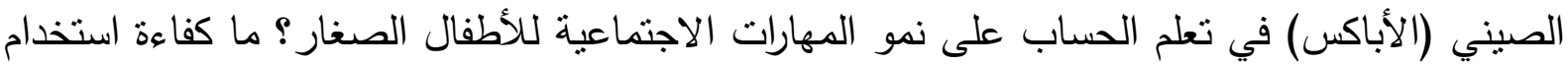

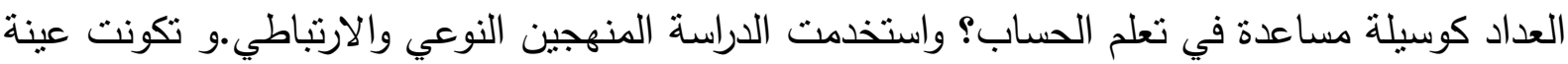

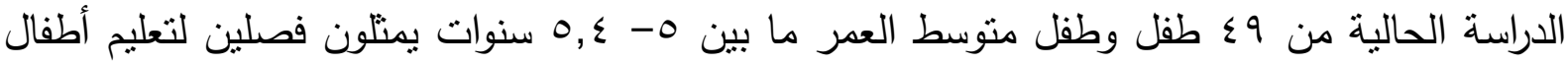

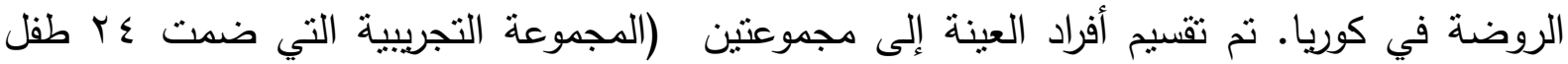

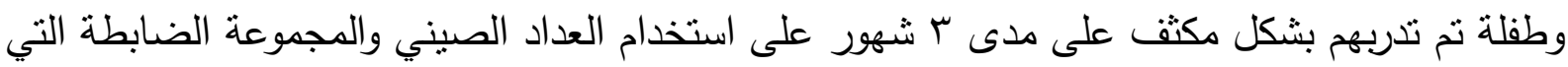

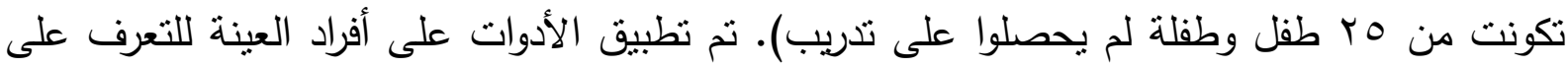

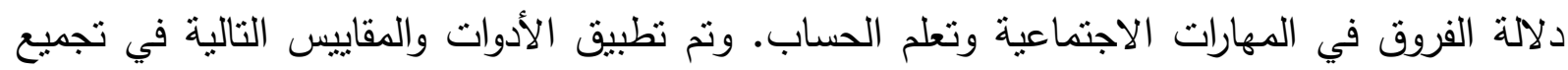

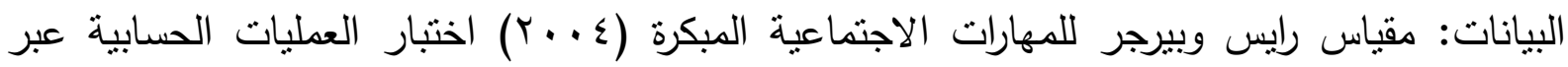

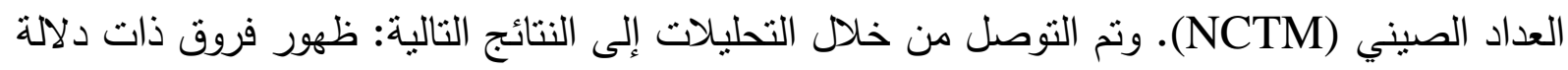

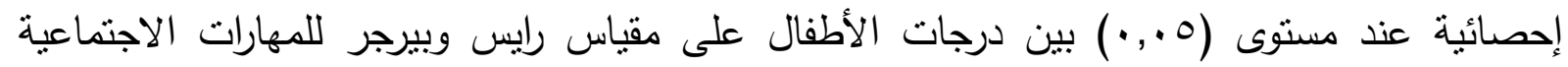

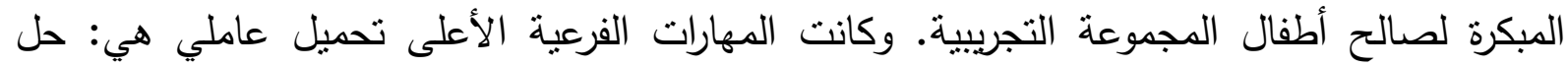




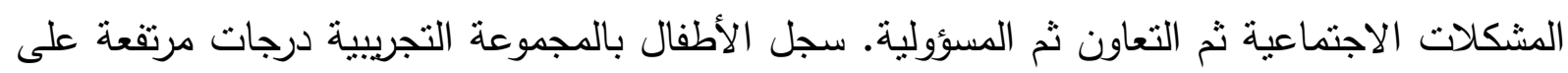
اختبار العطليات الحسابية عبر العداد الصيني. يبين (Nool, 2015 : 307 أن العداد الصيني يمتاز عن الحاسبات التقليدية بالخصائص

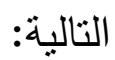
- - يوضح العداد الصيني للطفل آلية القيام بالعطلية الحسابية على عكس الحاسبات التقليدية التي تعطي الحلول مباشرةً. - يعمل العداد الصيني على زيادة مستويات التفكير الحسابي بالمقارنة مع الحاسبات.

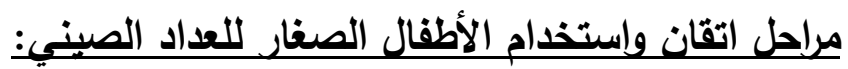

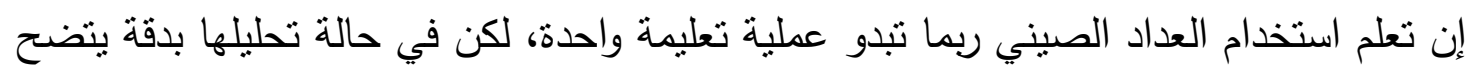

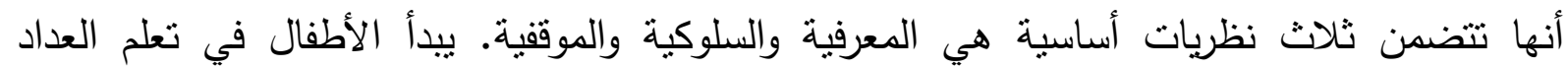

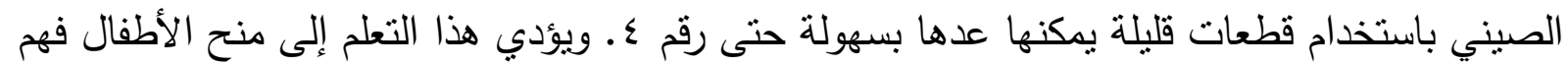

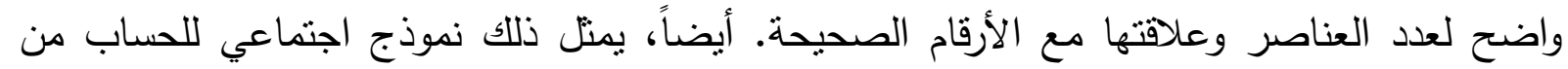

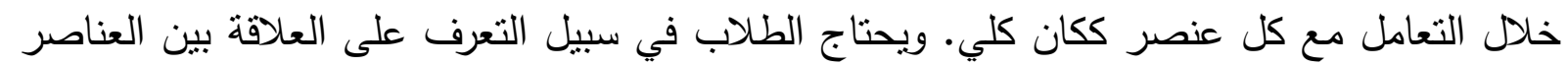

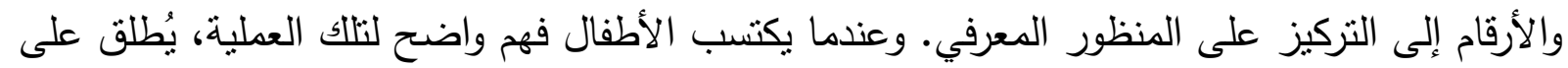
ذلك اسم التعلم الموقفي (Lee, \& Kato, 2017: 34). وصف (Wohlschlager, 2013: 709) مراحل التدريب على العداد الصيني في العطليات الحسابية كما يلي: - الئ أ- يتعلم الأطفال مفاهيم الحساب ويطبقون هذه المفاهيم على العداد الصيني.

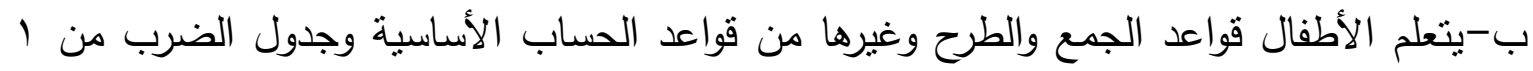
إلى 9. ت-يتقن الأطفال استخدام العداد الصيني بسرعة ودقة نتيجة لتعلم المفاهيم والاستجابة للمثيرات. ومن جانبه، صنف (Huang, Du, Yao, Wan, Wang, \& Chen, 2015: 661) مراحل اتقان العداد الصيني العقلي بين الأطفال الصغار كما يلي: : الصني:

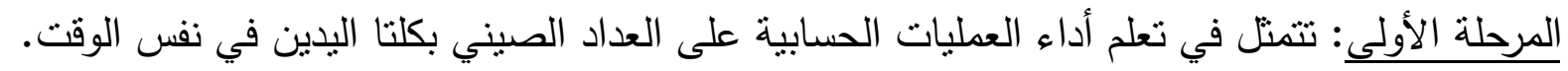

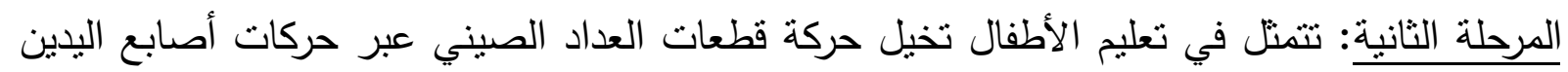

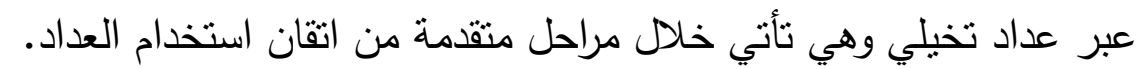

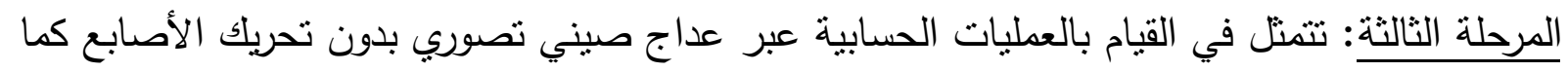
لو كان الطفل يعمل عبر "عداد صيني عقلي". لخص (Kolbert, \& Tauntom, 2014; 11 خصائص حل المشكلات في مرحلة الطفولة المبكرة في ضوء استخدام العداد الصيني على النحو التالي:

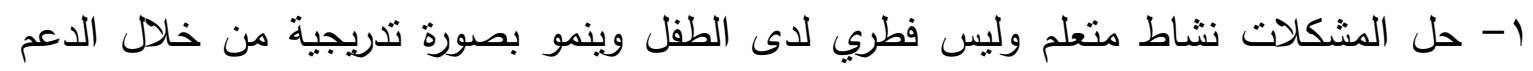

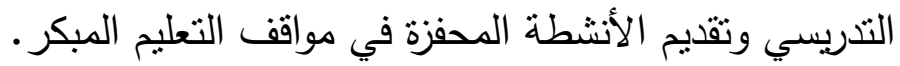

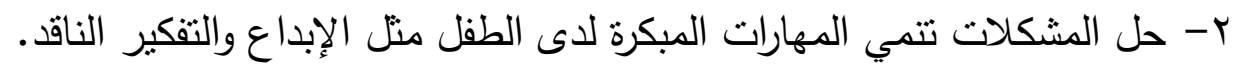

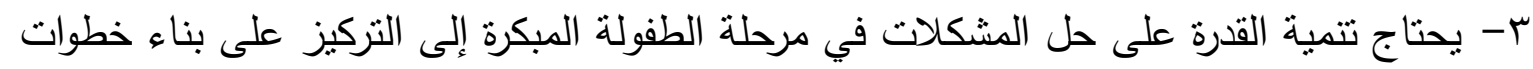
حل المشكلة أكثر من النتائج. 
ع- تخضع قدرة حل المشكلات في مراحل الطفولة المبكرة للتقييم. ويمكن أن يتم ذلك التقييم في مي التي

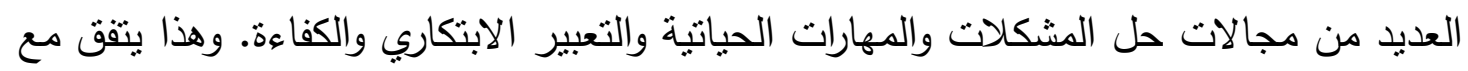
دراسة كاليفانو (10 • ب) بعنوان استخدام العداد الصيني في التدريب على المهارات الاجتماعية للأطفال.و هدفت الدراسة إلى التعرف على كفاءة استخدام العداد الصيني في تحسين المهارات

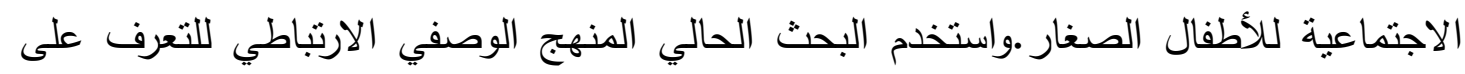

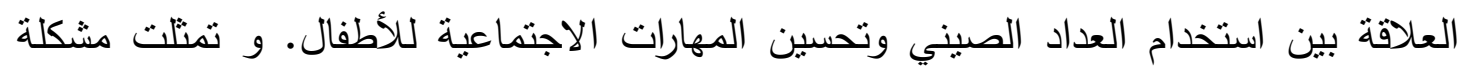
البحث في الإجابة على التساؤل التالية: هل يؤثز التدرب لى العداد الصيني على تتمية المهارات الاجتماعية للأطفال الصغار؟ تمنلت عينة البحث من من (T) ( ) طفل وطفلة متوسط أعمارهم 7 سنوات بأحد مواقف تعليم أطفال الروضة في مدينة تورينو الإيطالية بالإضافة إلى معلمات

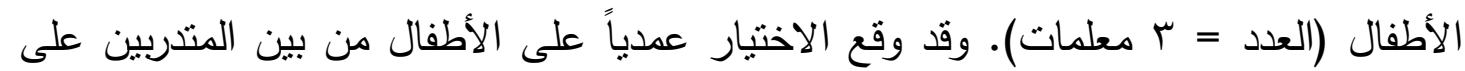
استخدام العداد الصيني في إجراء العمليات الحسابية. وقد تم تسجيل التفاعلات الاجتمعية للأطفال بالفيديو بغرض التحليل. تم تطبيق الأدوات والمقاييس التالية على الأطفال:تحليل الفيديو لتفاعلات الأطفال الاجتماعية. اختبار المهارات الاجتماعية المبكرة للأطفال (إعداد المؤلف). قائمة المهارات الاجتماعية أثناء ممارسة العداد الصيني - موجهة للمعلمات. وتم التوصل من الاهن خلال التحليلات إلى النتائج التالية:أظهرت النتائج في عمومها فاعلية العداد الصيني في تلتمية المهارات الاجتماعية للأطفال.سجل الأطفال درجات ما بين متوسطة إلى مرتفعة على اختبار المهارات الاجتماعية المبكرة للأطفال. حددت المعلمات بعض المهارات الاتهات الاجتماعية الأكثر

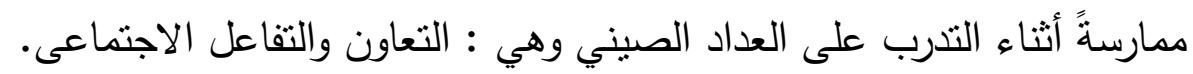

"ثاتيا: المهارات الإجتماعية Social skills:

هى مجموعة من الخبرات والأعمال المتعلمة والتي تمارس بشكل منتظم بحيث تسهم في تعديل السلوك، وذلك بالتخلي عن الاستجابات السلبية غير المقبولة اجتماعيا، وممارسة الاستجابات الإيجابية

(Riggio, Y, 2005: 324)

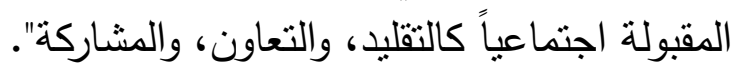

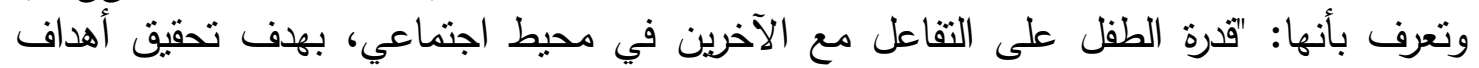
اجتماعية، وتؤدي إلى توافقه الاجتماعي، وتتنمل مجموعة الأنشطة التي يتعلمها الطفل ويكررها ويتدرب عليها

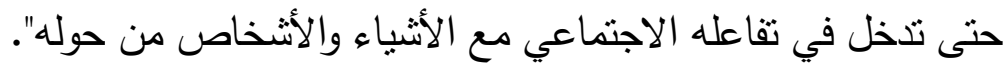

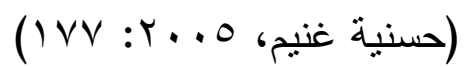

كما تعرف بأنها: "مجموعة من السلوكيات الاجتماعية التي يكتسبها الفرد وعن طريقها يحقق التكيف والتفاعل الإيجابي مع الآخرين في إطار يرتضيه المتمع حيث يتم استخدامها من أجل تحقيق

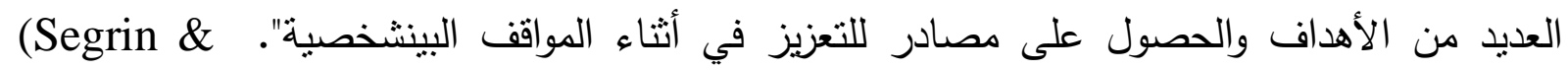
Flora, 2006: 166)

وتعرف بأنها: "عادات وسلوكيات مقبولة اجتماعياً يتدرب عليها الطفل إلى درجة الإتقان والتمكن من خلال التفاعل الاجتماعي الذى يعد بمثابة مشاركة بين الأطفال في مواقف الحياة اليومية وتقيد في دئي

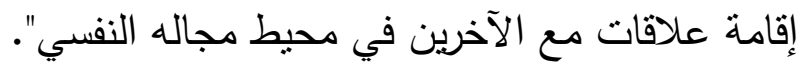

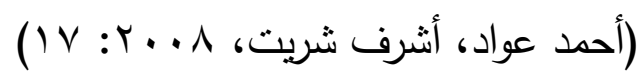


عرفها "كومبس Combs" و "سلابي Salaby" أنها القدرة على التفاعل مع الآخرين في إطار اجتماعي محدد، وبأساليب معينة مقبولة اجتماعياً.

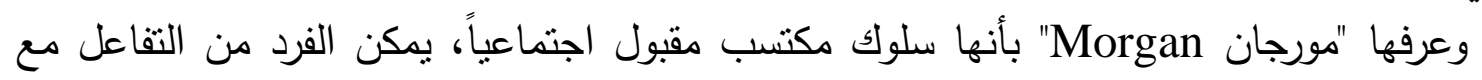
(Stigler and Smith, 2005: 1259-1270) الآخرين تفاعلاً إيجابياً.

\section{ويالنظر إلى التعريفات السابقة للمهارات الاجتماعية نجد أنها:}

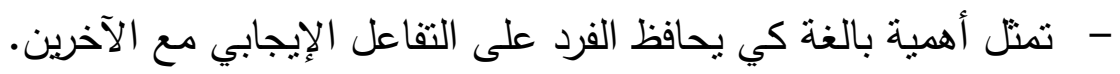

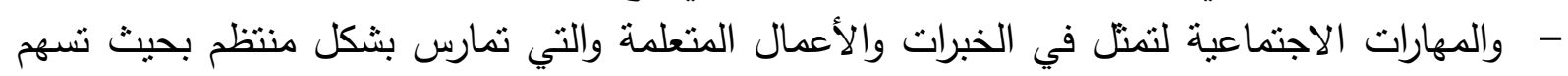

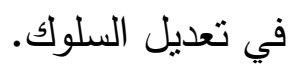

- - تعطي هذه التعريفات أهمية كبرى للمعايير الاجتماعية والثقافية باعتبارها محدداً للسلوك المقبول وغير المقبول.

مكونات المهارات الاجتماعية:

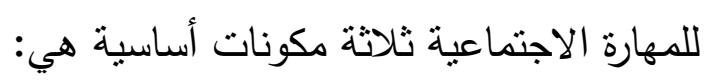
1- المكونات المعرفية:

وهي غير ملاحظة وتتشمل أفكار الفرد واتجاهاته ومدى معرفته بالاستجابات المناسبة في المواقف القات

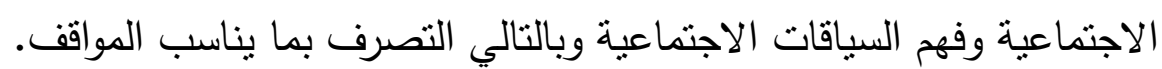
(Gresham, \& Van, \& Cook, 2006: 363)

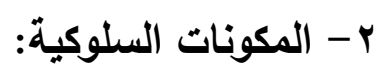

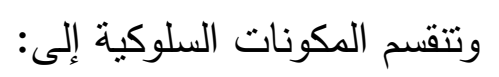

- سلوك اجتماعي لفظي: وهذا النوع من السلوك له أهمية كبرى في مواقف التفاعل الاجتماعي فهو الهواء

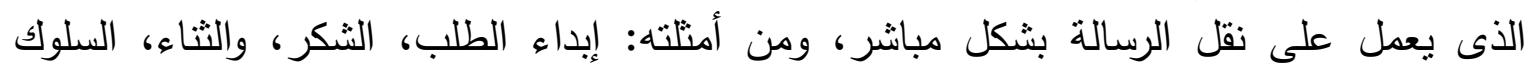
التوكيدي. - سلوك اجنماعي غير لفظي: ويشمل لغة الجسد والإيماءات، ويقال إن لها المصداقية الأكثر في (Gresham, Van, \& Cook, 2006: 363) التعبير من السلوك اللفظي.

ب- المكونات الوجدانية الانفعالية:

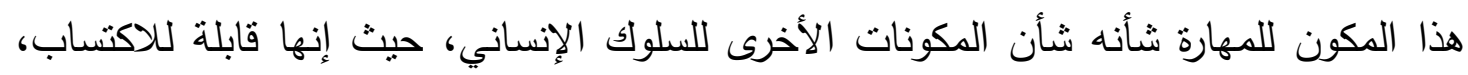

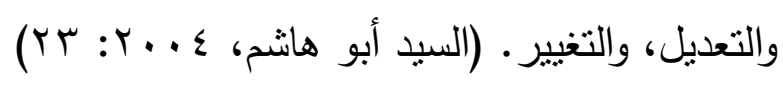
تصنيف المهارات الاجتماعية: أولاً: مهارة التواصل مع الآخرين:

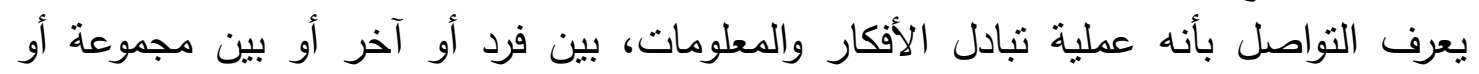

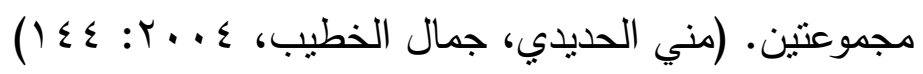

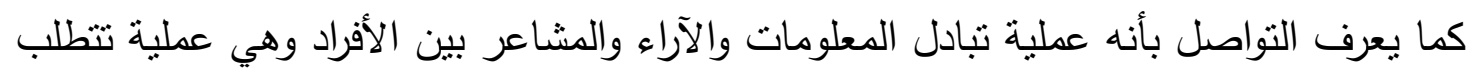

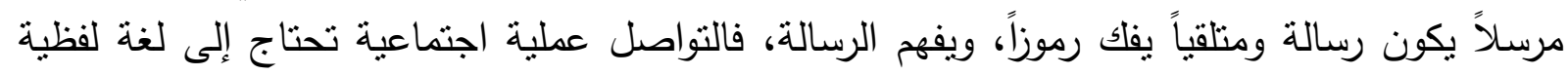

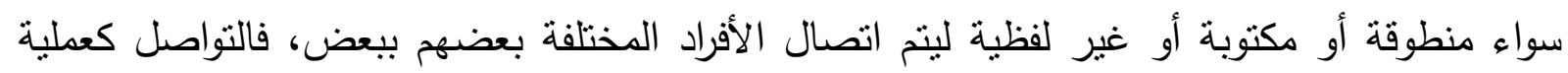


يفترض فيها أن مكونات التفاعل دينامية وليست ساكنة في طبيعتها، فالتغير في جانب من جوانب التواصل قد يؤدي إلى تعديل النواصل ككل.

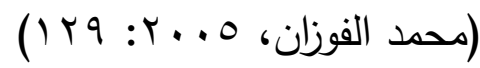

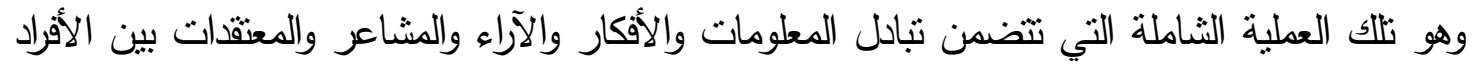

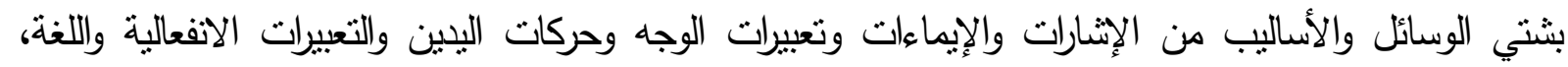

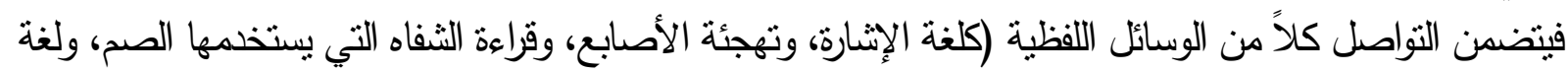

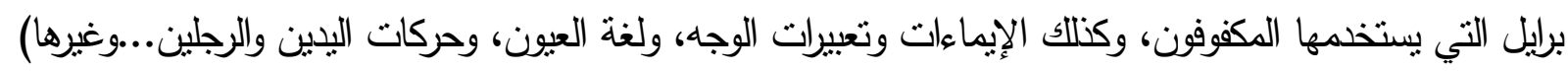
ولنلك يعد التواصل أعم وأثندل من اللغة والكلام واللغة والنطق.

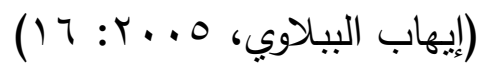

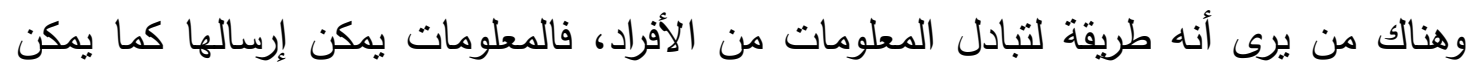
استقبالها بطرق متعددة، تتراوح ما بين الكلمة أو الإثارة من خلال رسالة معينة.

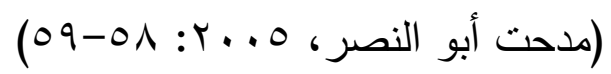

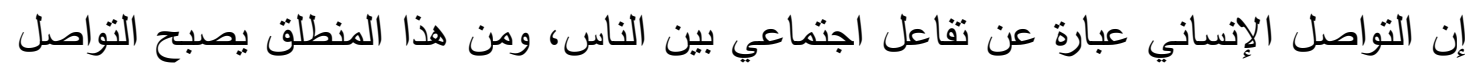

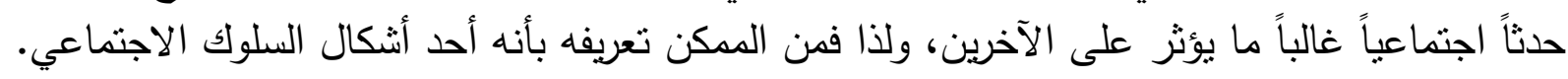

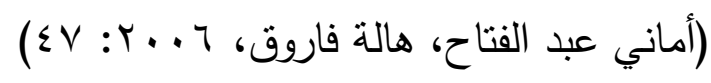

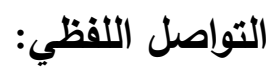

يحتوى التواصل اللفظي على عمليتين أساسيتين هما: الإرسال، والاستقبال.

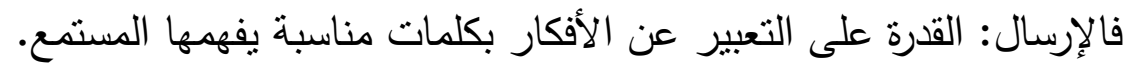

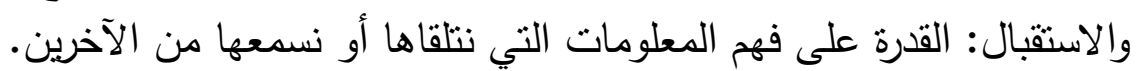

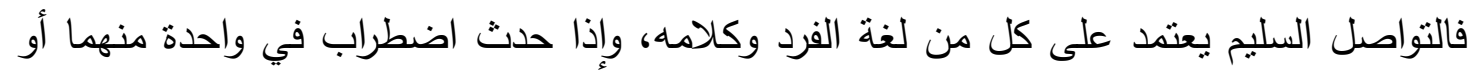
الاثثين يؤدي إلى اضطراب التواصل.

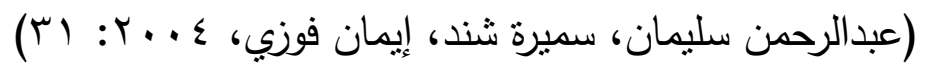

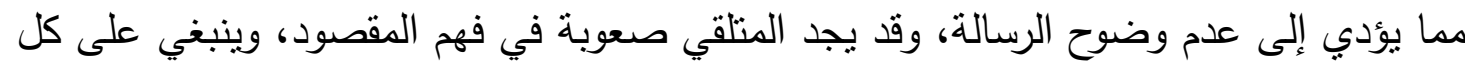

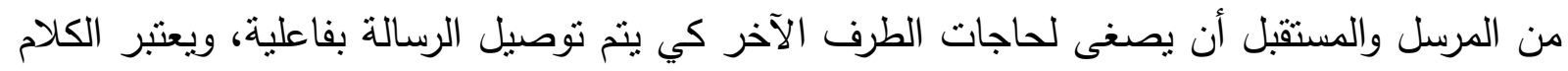

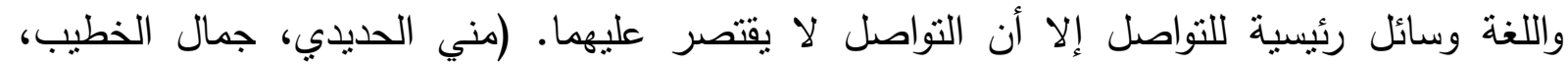

وهناك أبعاد أخرى وهي الأبعاد غير اللفظية وتتثمل الإيماءات، الإثارات، والمسافة الجسمية، التهاتية

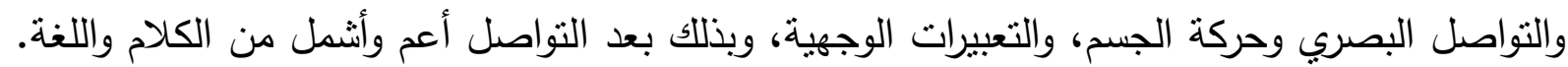

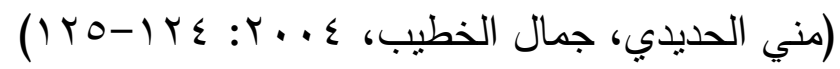

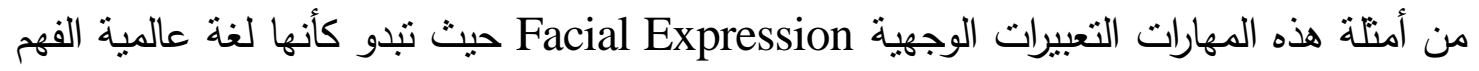
أي أن جميع البشر يستطيعون فهم معناها، ومثال آخر هو الإيماءات Gestures التئي التي تعتمد بشكل كبير

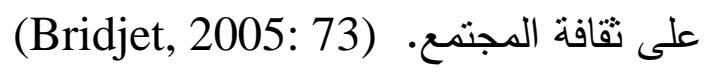




\section{أهمية مهارة التواصل مع الآخرين:}

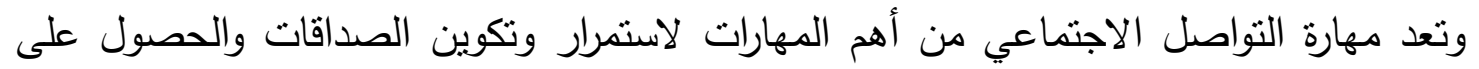

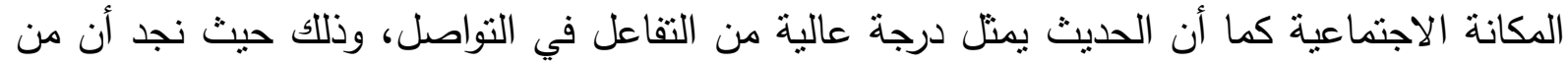

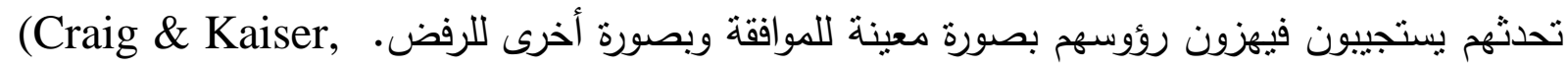
2000: 35)

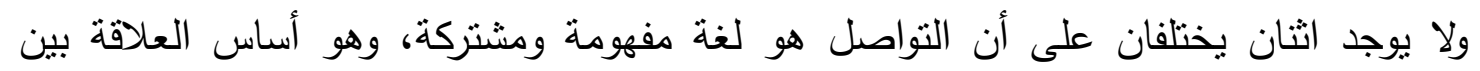

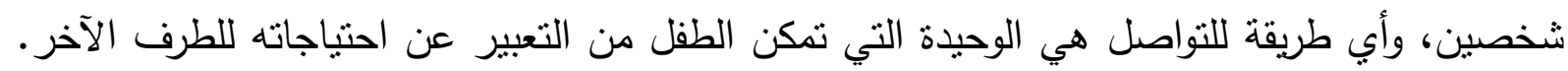

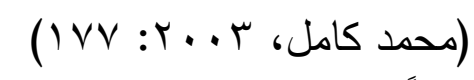

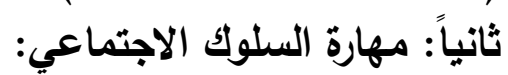
وتعرف مهارة السلوك الاجتماعي على أنها: تفاعل بين الأفراد وليس من الضروري أن أن يكون التقاعل

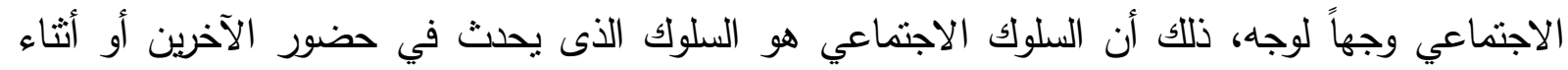

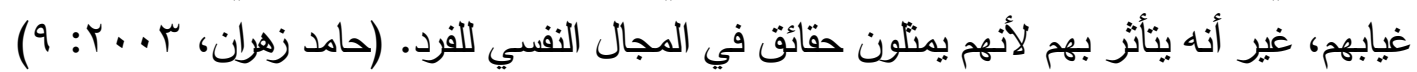

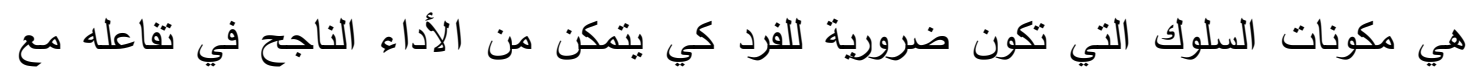

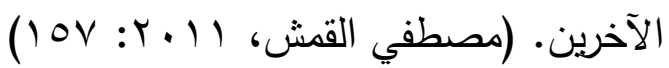
وهي السلوك المحدد لعلاقات الفرد بغيره داخل المجتمع وهو المسؤول عن تكوين العلاقات

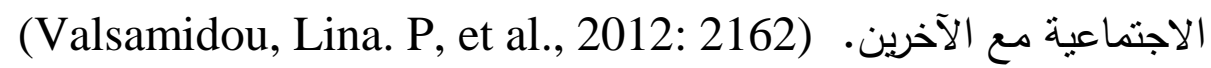

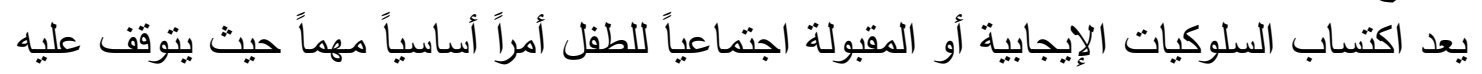

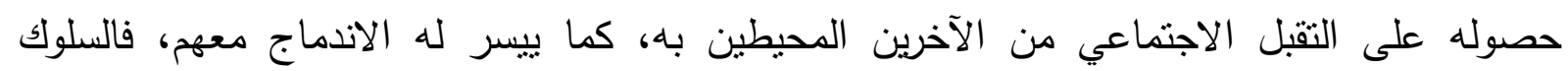

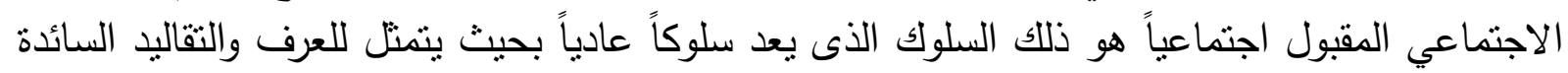

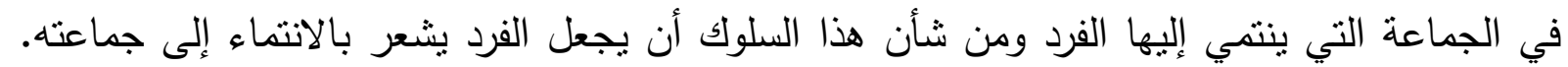

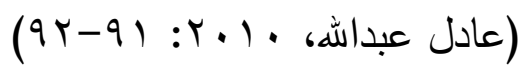

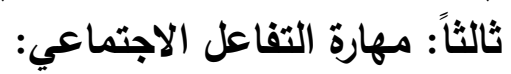

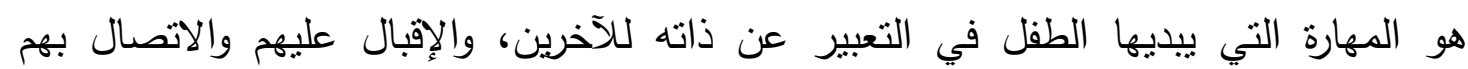

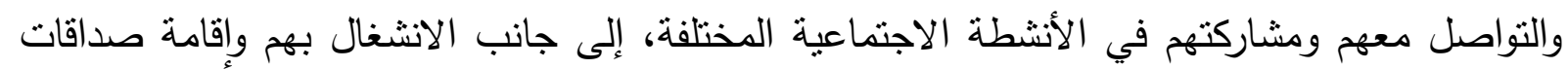

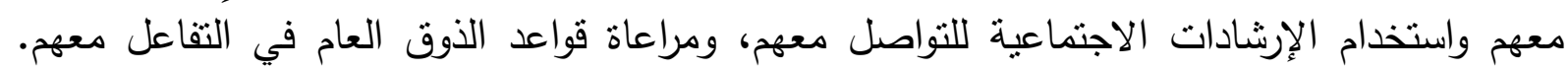

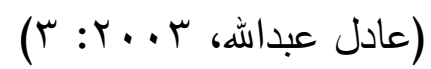
وتمثل مهارات التفاعل الاجتماعي مدى واسعاً من السلوكيات الاجتماعية اللازمة للتواصل

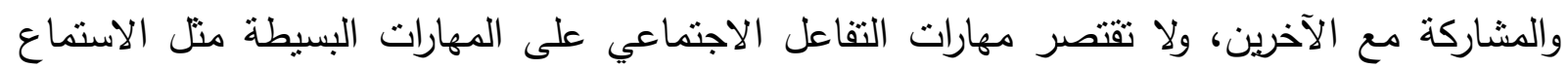

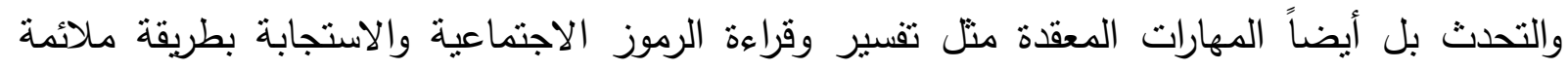

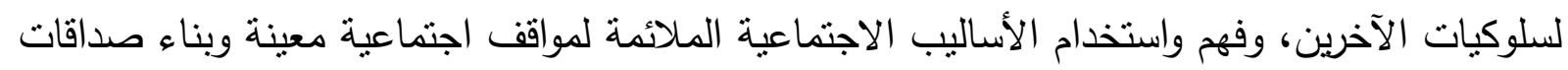
وعلاقات حميمة مع الآخرين.

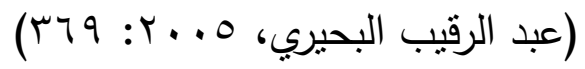

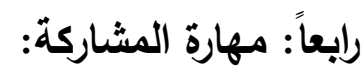
هي المهارات التي تساعد الفرد على إقامة علاقات اجتماعية إيجابية مع الغير وتقبل الآخرين.

(Merrell, 2001: 136) 
وتتمنل المهارة في التعبير عن الذات والاتصال بالآخرين ومثاركتهم في الأنثطة الاجتماعية وإقامة حوار

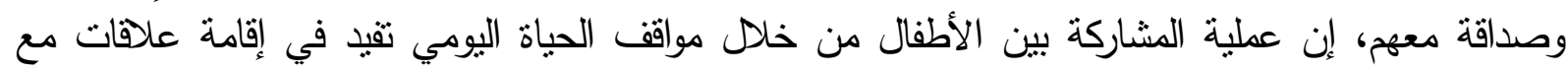

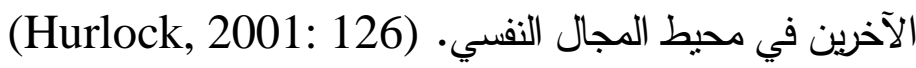
ولكي تتمو هذه المهارة يحتاج الطفل إلى التتوع في أساليب اختلاطه بغيره من الأطفال ويحتاج

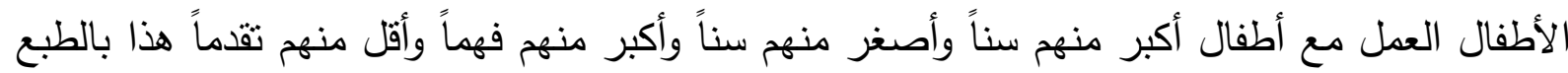

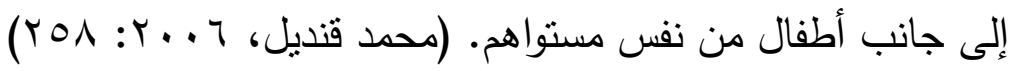

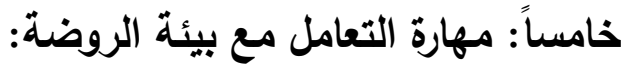
تتضمن هذه المهارة القدرة على إظهار المهارات اللازمة للتفاعل مع أفراد ومجريات وأحداث البيئة

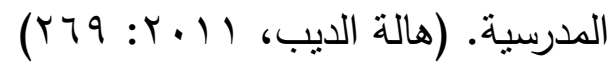
كما أن الطفل يستطيع أن يتعلم داخل المدرسة العديد من المفاهيم والمهارات الاجتماعية منل

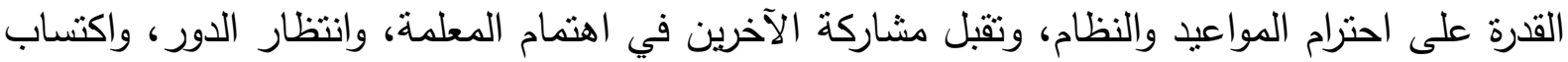

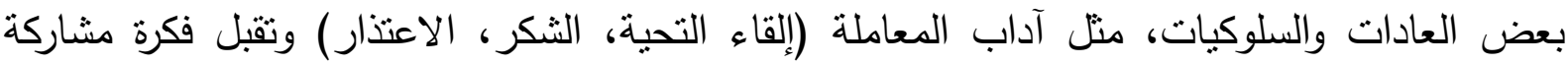

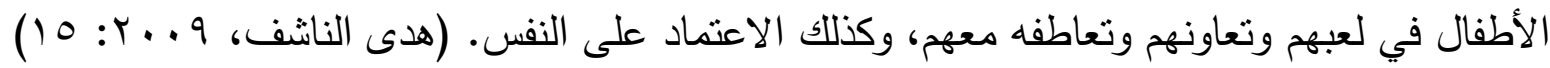

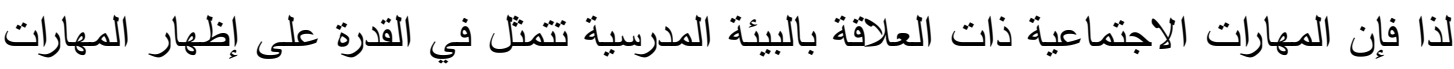

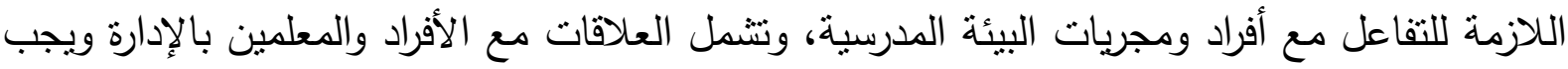

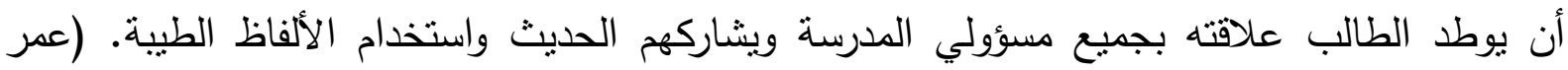

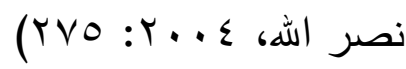
أهمية اكتساب المهارات الاجتماعية:

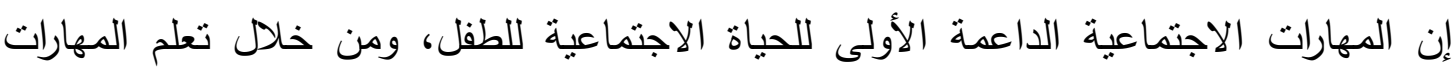

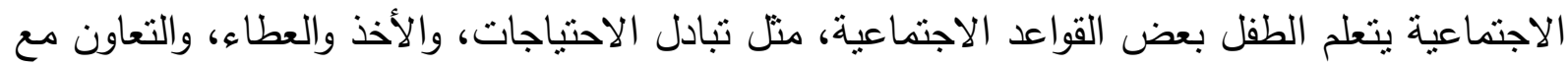

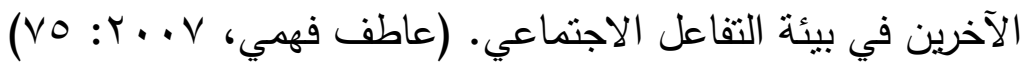

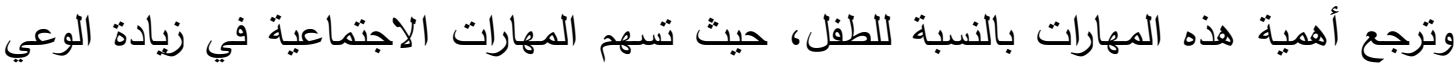

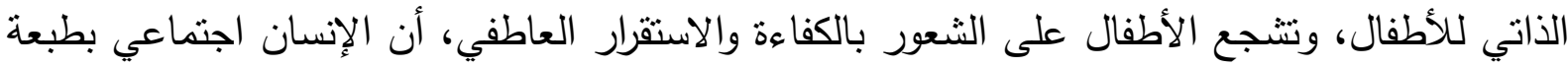

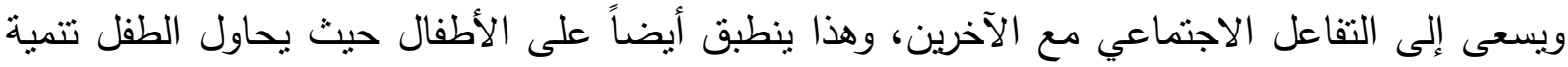

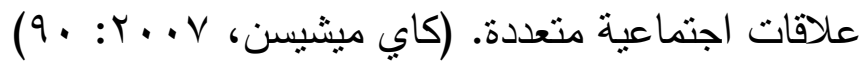

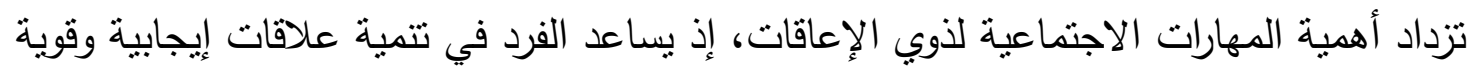

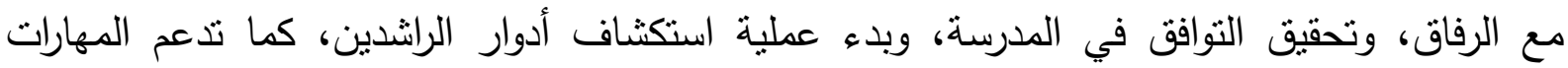
الاجتماعية النمو الإيجابي للعلاقات الناجحة مع الراثندين ومن حوله الأسرة والرفاق. :Chen, 2006)

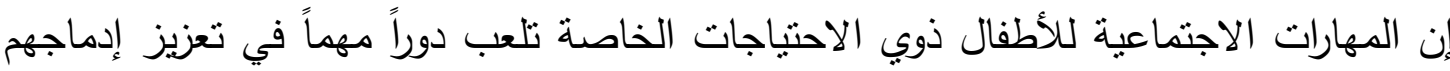

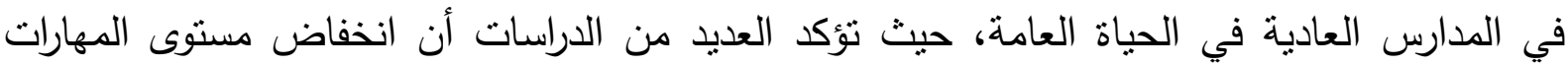

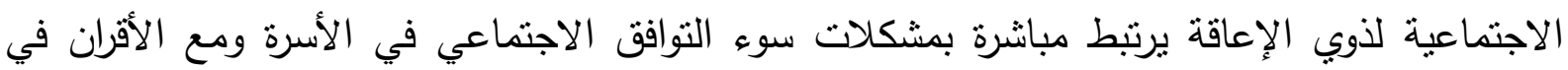

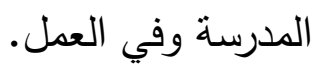

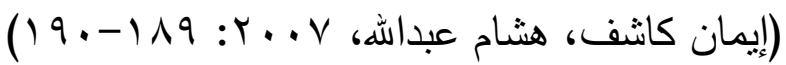




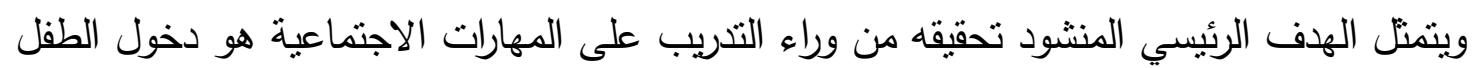

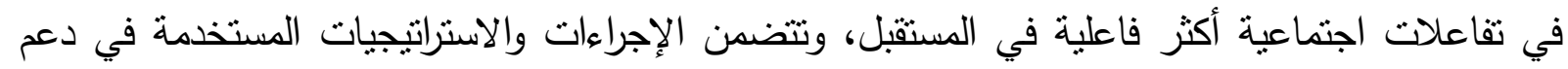

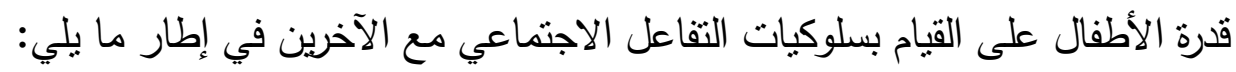

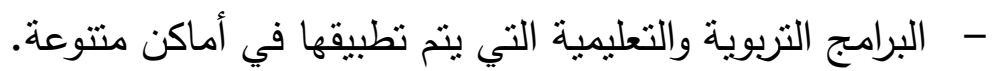

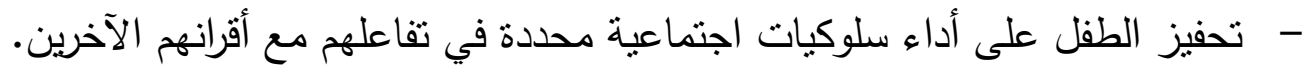
- - التعزيز الإيجابي لسلوكيات أو أنماط محددة من التفاعلات الاجتماعية.

(Cheng-Husien, Wu, 2007: 1-2)

إن المهارات الاجتماعية لها أهمية كبيرة في حياة الطفل والهدف من تتميتها هو مساعدته على الهات

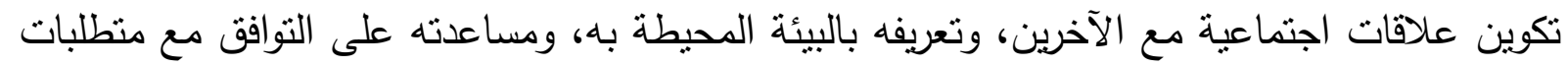

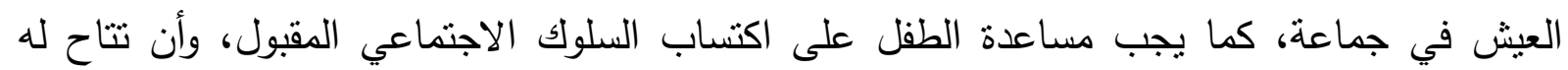

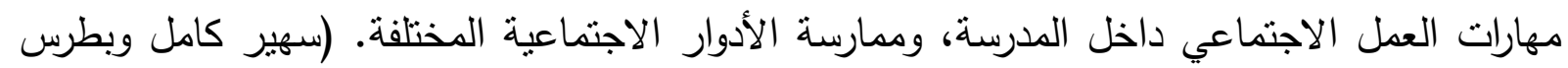

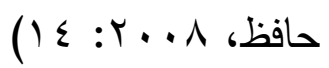
إن كان نجاح الطفل في التكيف مع العلاقات الاجتماعية الخارجة يتأثر بنوع الخبرات الاجتماعية

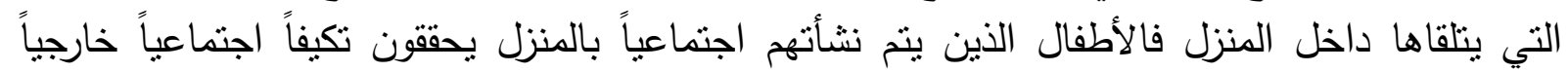

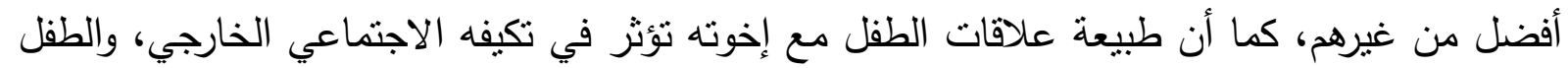

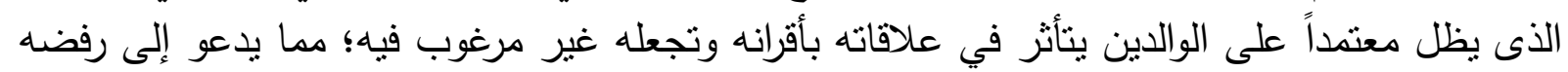

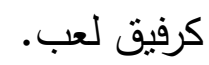

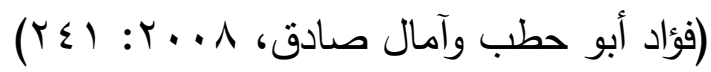

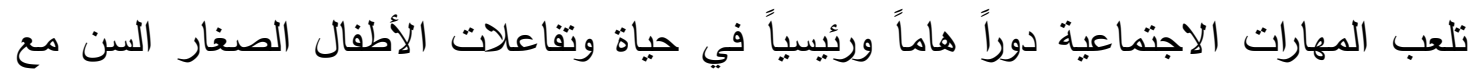

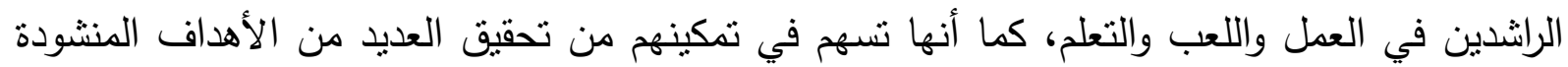

(Stahl, K., 2008: 4)

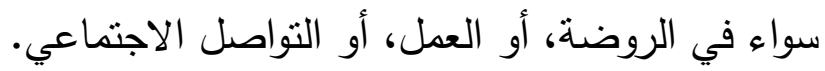

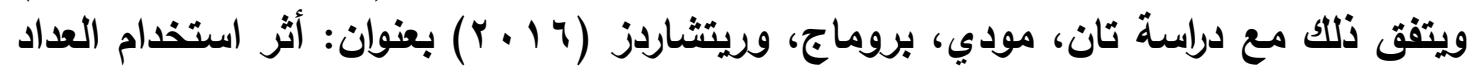

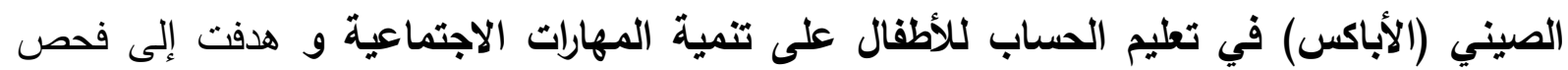

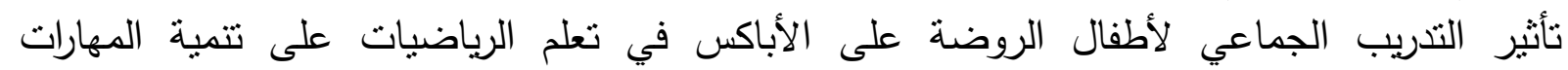

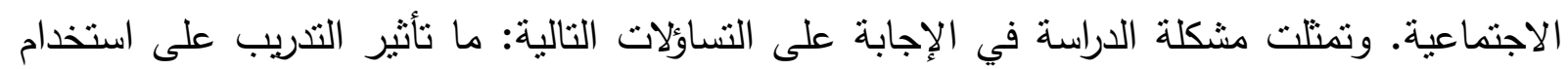

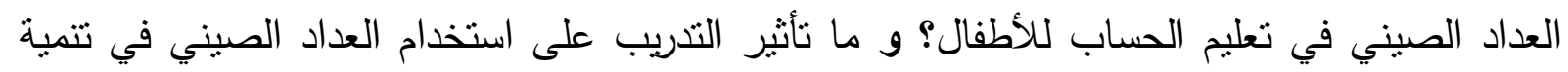

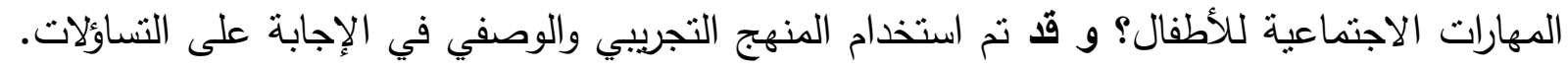

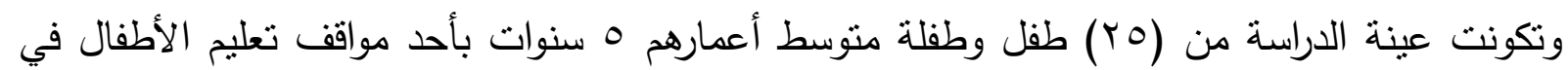

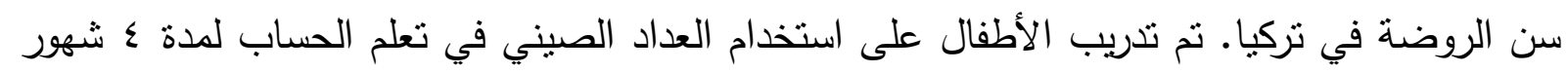

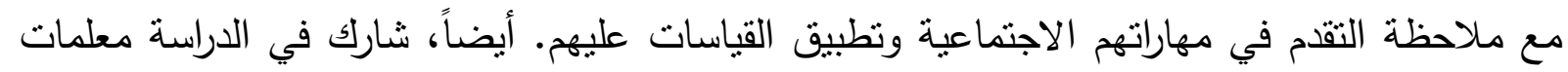

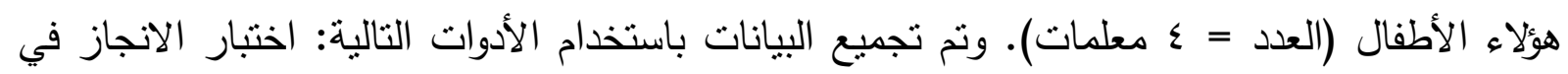

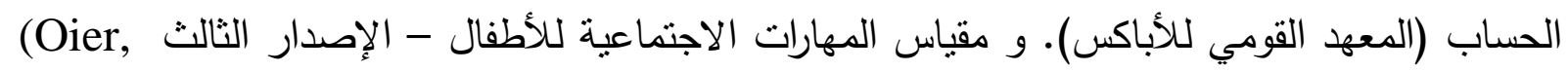

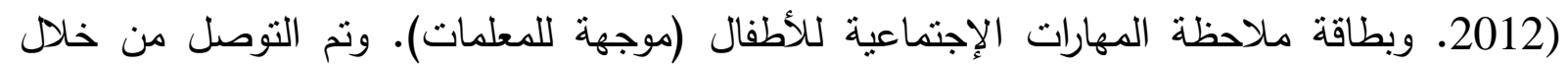

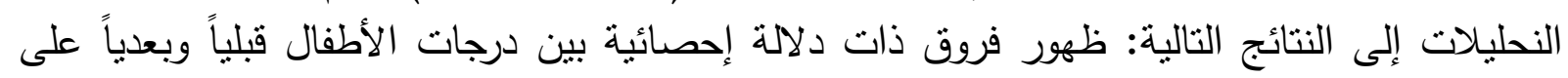
اختبار الإنجاز في الحساب لصالح التطبيق البعدي، وهو ما يبرهن على فلى فاعلية التنريب على التى العداد 
الصيني في تحسين تعلم الأطفال للحساب. ظهور فروق ذات دلالة إحصائية بين درجات الأطفال قبلياً

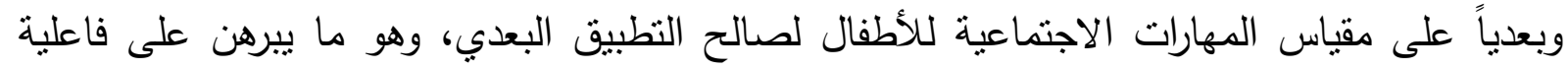

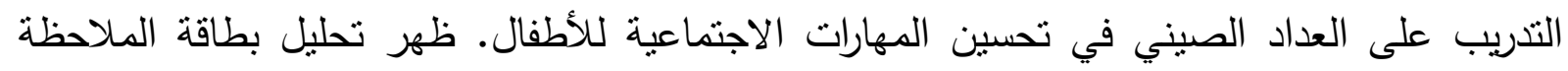

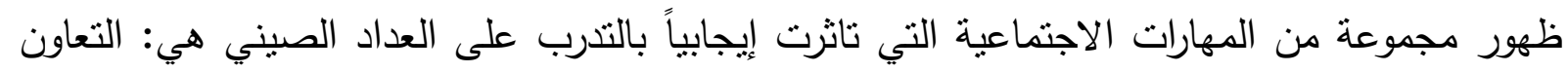
والمسؤولية والتعلم الجماعي.

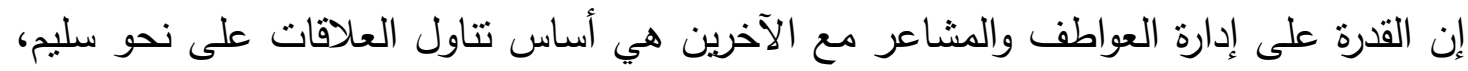

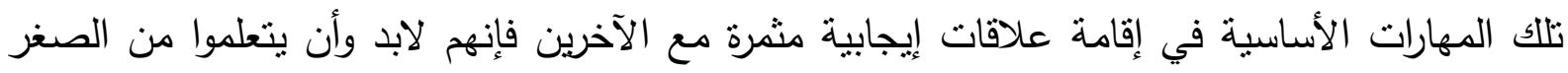

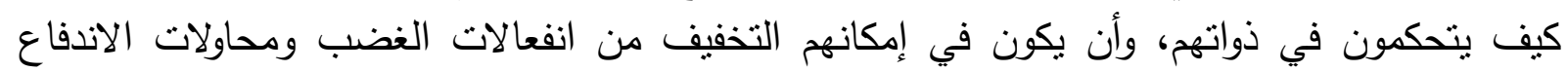

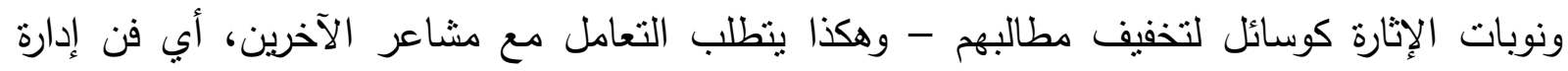

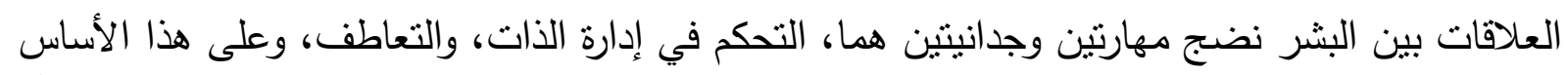

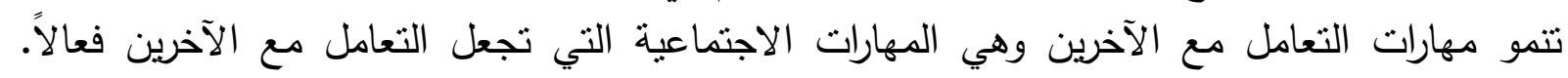

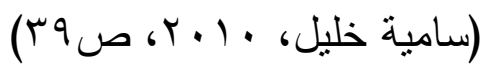

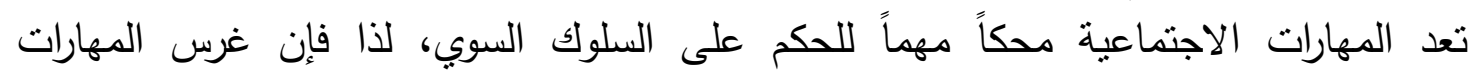

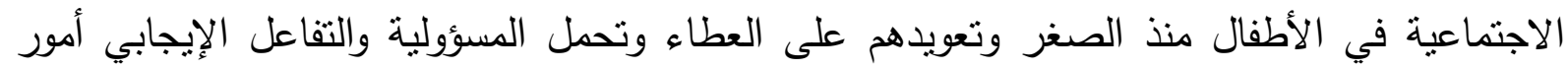

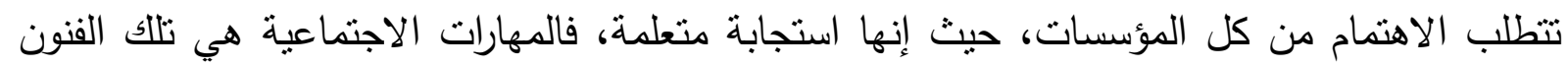

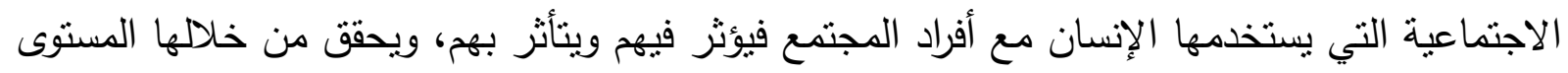

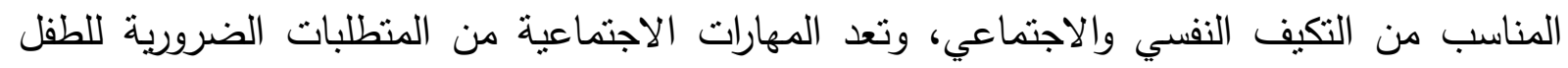

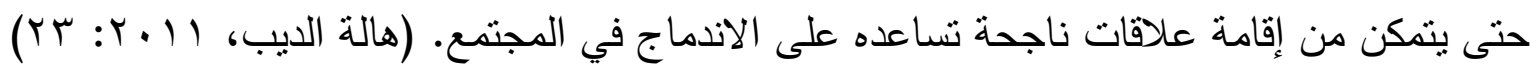

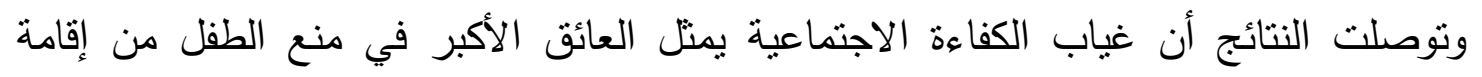

$$
\text { علاقات هادفة مع الآخرين. }
$$

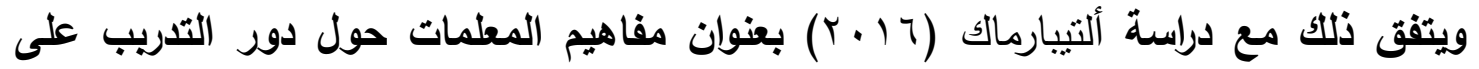

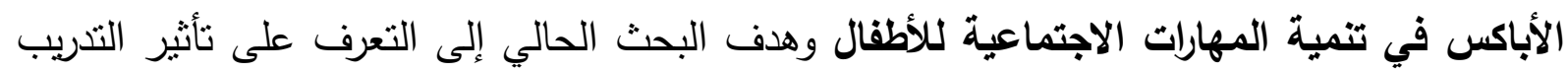

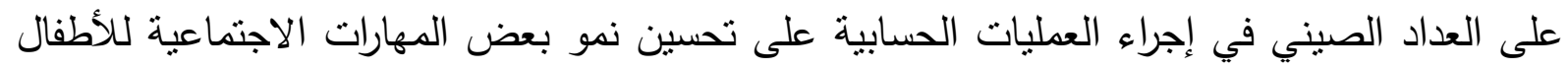

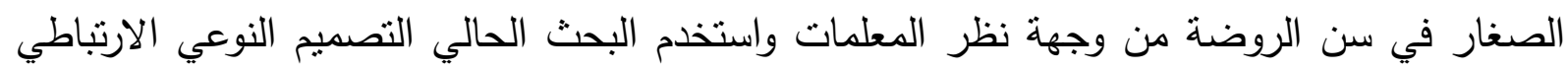

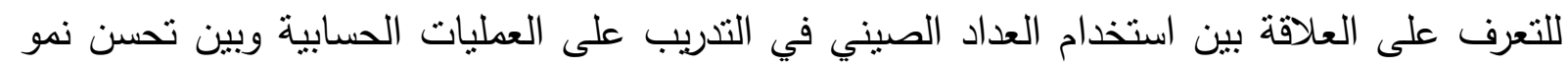

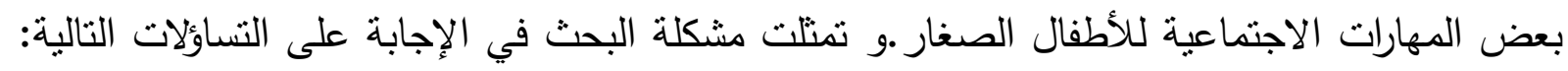

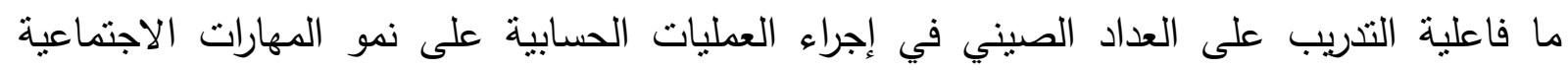

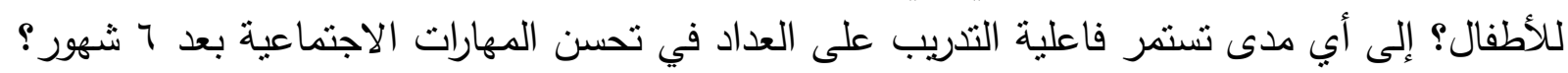

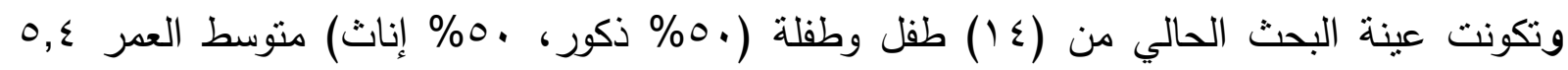

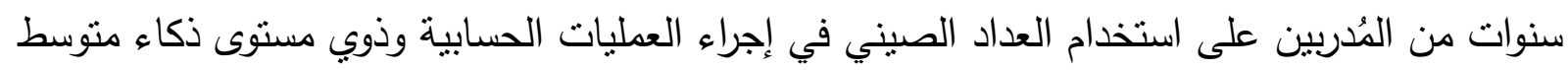

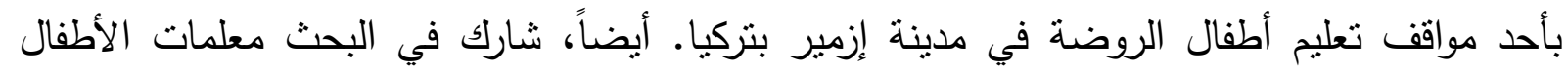

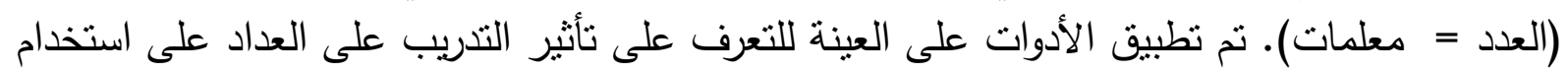

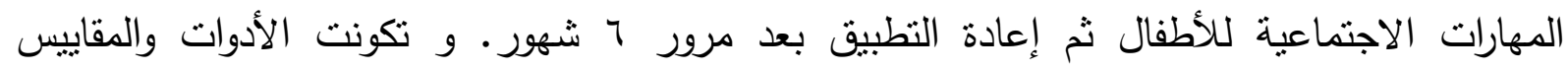

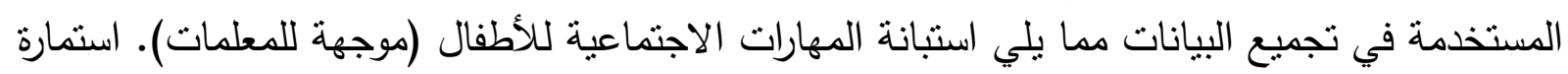

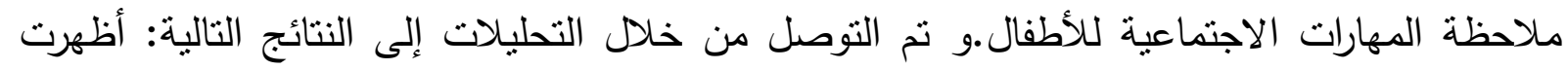


استجابة المعلمات على استبانة المهارات الاجتماعية نمو في المهارات الاجتماعية للأطفال نتيجة للتعلم

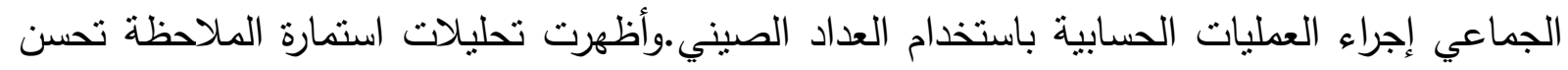

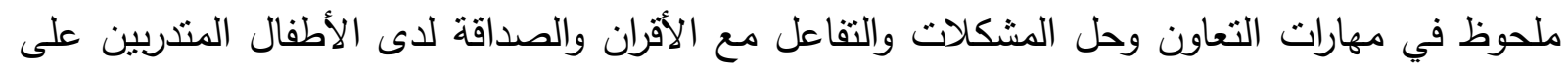

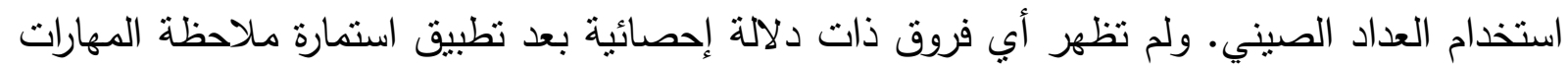

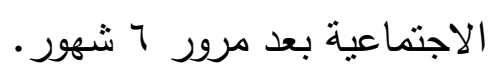

استراتيجيات اكتساب المهارات الاجتماعية:

هناك بعض الاستراتيجيات المستخدمة في تتمية المهارات الاجتماعية وهي:

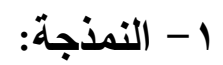

ويقصد بها إتاحة نموذج سلوكي مباشر شخصي أو ضمني تخيلي للمندرب؛ حيث يكون الهدف هو توصيل معلومات معينة للمتدرب بغرض إحداث تغير مبات محدد في سلوكه.

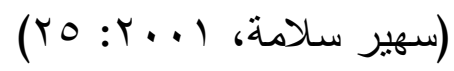

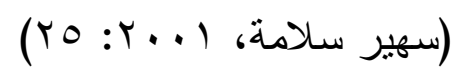

هو الجائزة أو الحدث السار الذى يعقب سلوكاً معيناً مما يقوى هذا السلوك.

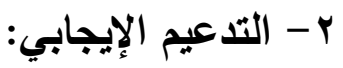
r- الحث (التلقين):

وهو يشير إلى المنبهات السابقة التي نساعد على إثارة السلوك، وتجعل الفرد يقوم بالسلوك

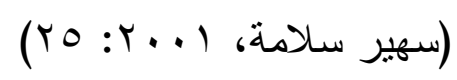

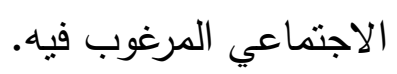

ه - و التثكيل:

هو منهاج التعلم الاجتماعي، يقوم فيها الفرد بتمثيل الجوانب من المهارات الاجتماعية حيث

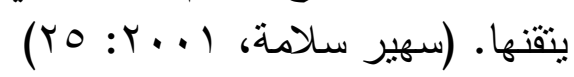

צ- التدريب على السلوك التوكيدي:

يظهر السلوك التوكيدي في العلاقات الثخصية، ويتضمن التعبير الصادق والمباثر عن

الأفكار، والمشاعر الثخصية.

نظريات المهارات الاجتماعية:

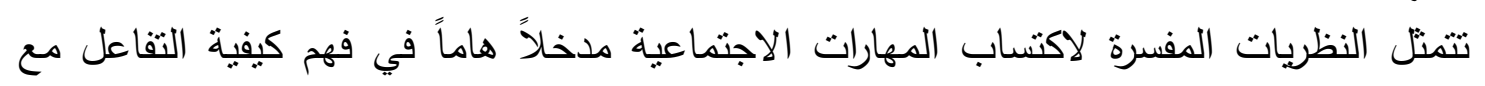

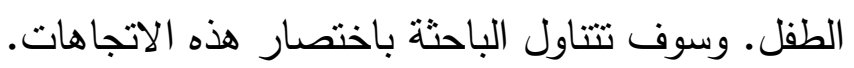

1- نظرية النضج:

تنشير نظرية النضج إلى أن العوامل البيولوجية هي المسؤولة عن نضج الطفل في كافة جوانب

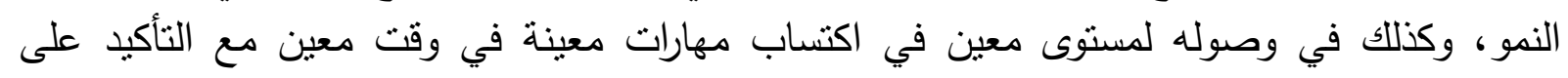

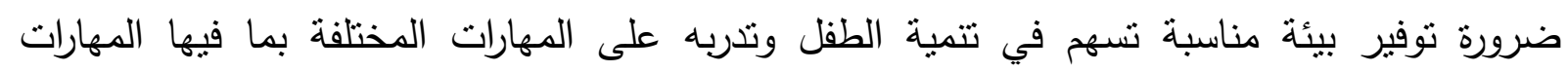
الاجتماعية عند وصوله إلى مرحلة النضج المناسبة. 


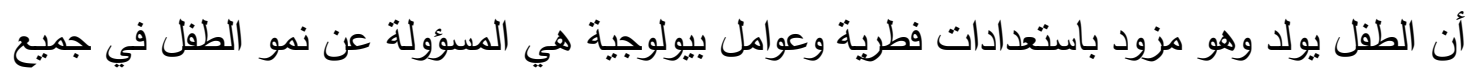

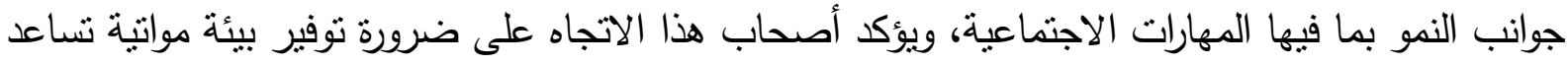

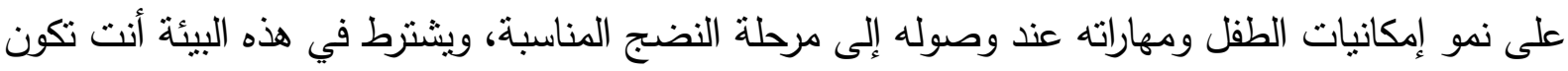

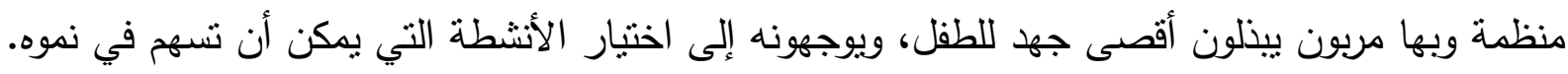

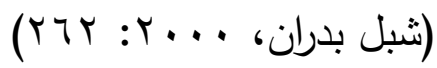

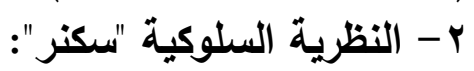

أكدت هذه النظرية على أن التعزيز أساس لاكتساب السلوك؛ ولذلك أطلق على نظريته نظرية

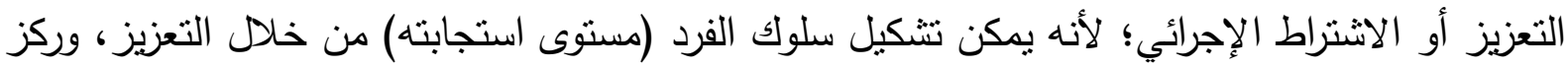

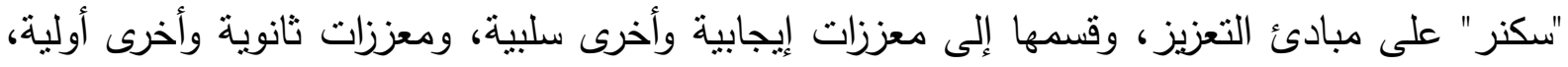
وأهتم بجداول التعزيز وأوضح فيه التعزيز وفيز المستمر والمتقطع (الزمني، والنسبي).

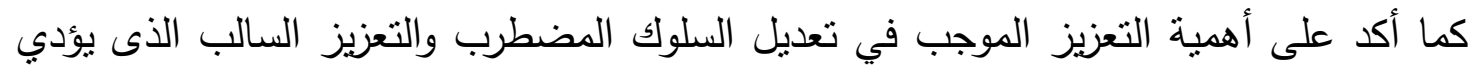

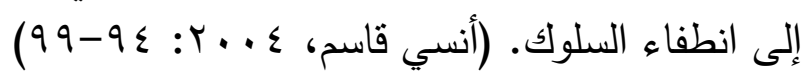

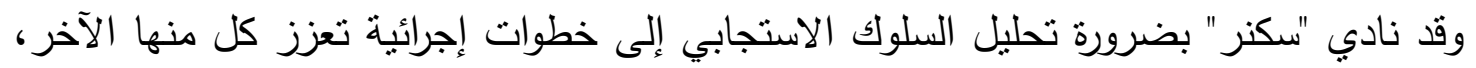

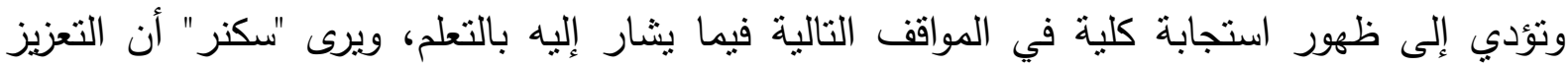

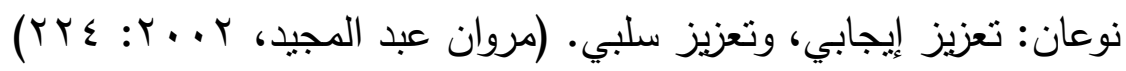
ب- نظرية التطلم الاجتماعي "باندورا":

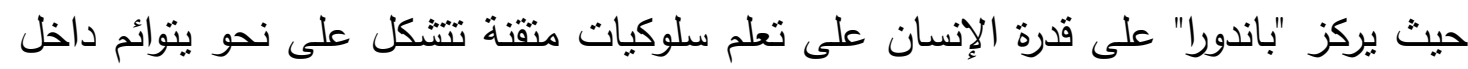

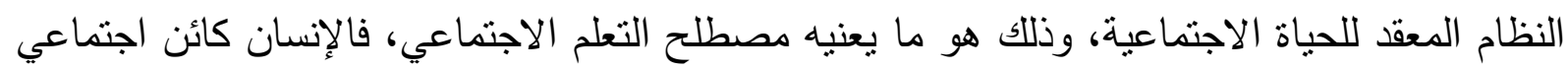
يعمل وفقاً لمبادئ السلوك الذى يلاحظه في الآخرين.

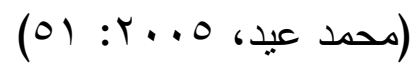

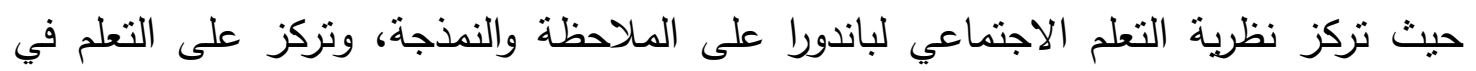

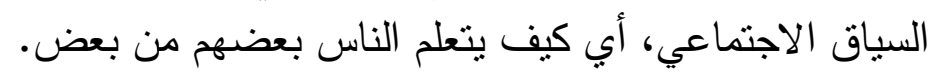

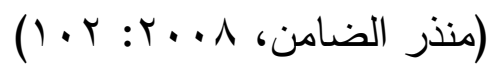

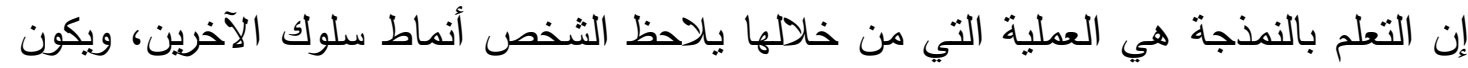

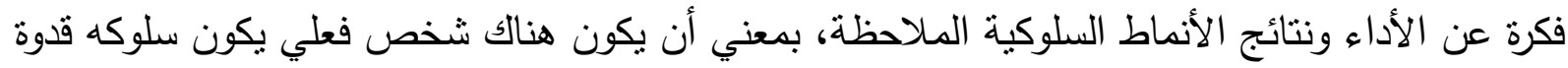

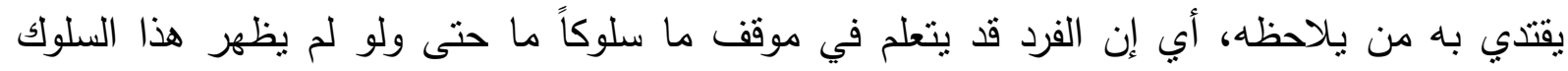

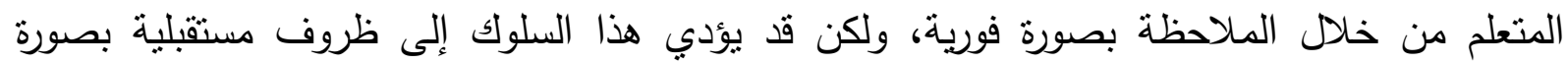

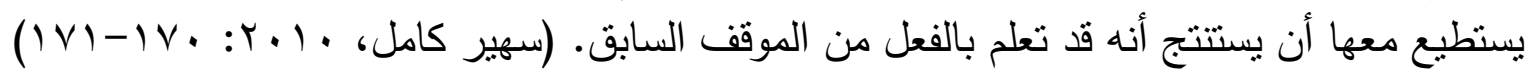

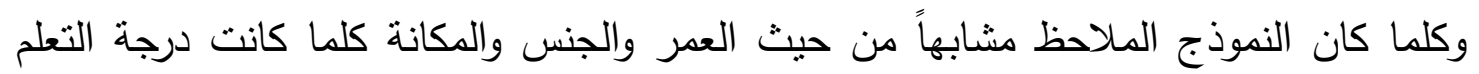

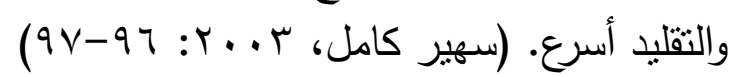
؛ - نظرية العقل Theory of Mind (TOM)

وتتشير نظرية العقل إلى قدرة الفرد على فهم عقول الآخرين أو ما يجري في عقول الغير، وتقدير

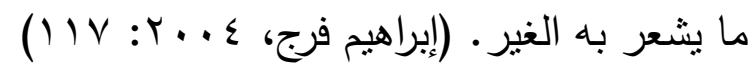


أبعاد المهارات الاجتماعية Dimensions of social skills: 1- المهارات الاجتماعية العامة:

وتتثمل السلوكيات المختلفة المقبولة اجتماعياً والتي يمارسها الفرد بشكل لفظي أو غير لفظي

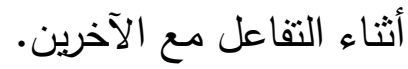
r - ب المهارات الاجتماعية الثخصية: ويقصد بها التعامل بشكل إيجابي مع الأحداث والمواقة الثبات الاجتماعية. r- مهارات المبادأة التفاعلية: وتثمثل في القدرة على المبادرة بالحوار ، والمشاركة، والتفاعل. ع - مهارة الاستجابة التفاعلية: وهي القدرة على الاستجابة لمبادرات الغير من حوار أو شكوى أو طلب البهابت المساعدة. ه- المهارات الاجتماعية ذات العلاقة بالبيئة المدرسية:

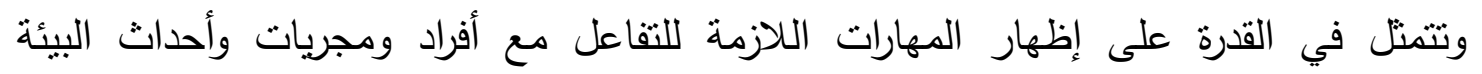
الددرسية، وتتشمل العلاقات مع الطلاب والمعلمين وطاقم الإدارة وأصحاب الوظائف المساندة.

צ- المهارات الاجتماعية المتعقة بالبيئة المنزلية: ممارسة المهارات مع الأبناء، الابتسامات، الهائة الهايا والتعبيرات المناسبة لها مردودها الإيجابي على العلاقات الأسرية.

تصنيف المهارات الاجتماعية Classification of Social Skills: الاتربة يصنف (Giler, 2001:101) المهارات الاجتماعية إلى أربعة أنواع منها:

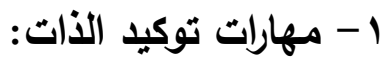
وهي تتعلق بمهارات التعبير عن المشاعر والآراء والدفاع عن الحقوق، وتحديد المهارات في

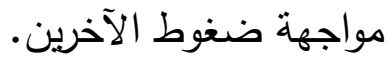

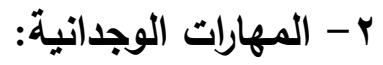

وتهتم بتيسير إقامة الفرد لعلاقات وثيقة وودية مع الآخرين، وإدارة التفاعل معهم.

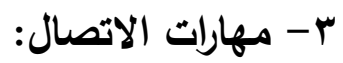

تتضمن مهارات الإرسال، وهي تعبر عن قدرة الفرد على نوصيل المعلومات التي يرغب في في نقاتها للآخرين لفظياً أو بشكل غير لفظي، من خلال عمليات نوعية، كالتحدث والحوار والإشارات الإنتماعية.

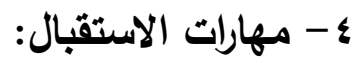
وتعني مهارة الفرد في الانتباه وتلقي الرسائل والمهارات اللفظية وغير اللفظية من الآخرين. ه- مهارات الضبط والمرونة الاجتماعية والانفعالية: وتنثير إلى قدرة الفرد على التحكم بصورة مرنة في سلوكه اللفظي وغير اللفظي الانفعالي، خاصة في موقف التفاعل مع الآخرين.

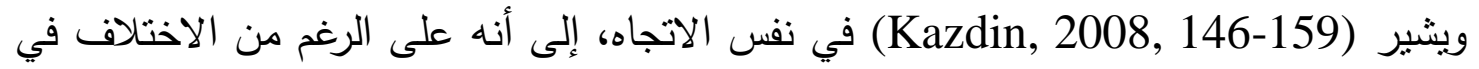

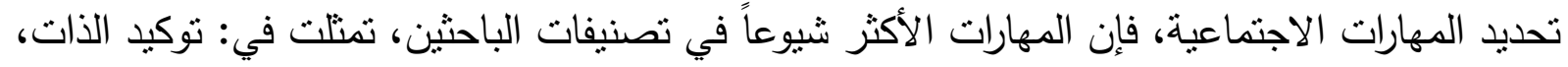

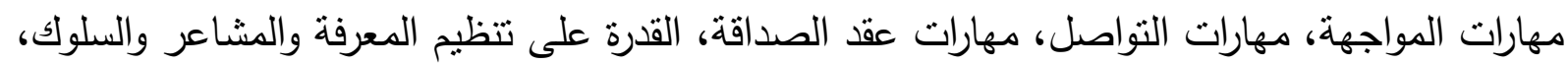


والتي تعكس القدرة على ضبط أو تتظيم الذات ويمكن تصنيف المهارات الاجتماعية، على ضوء بعدين

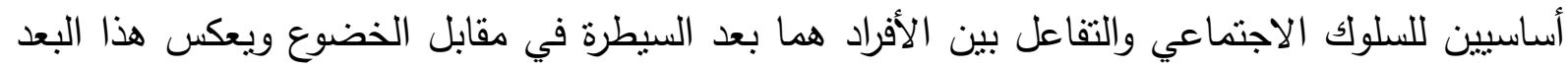

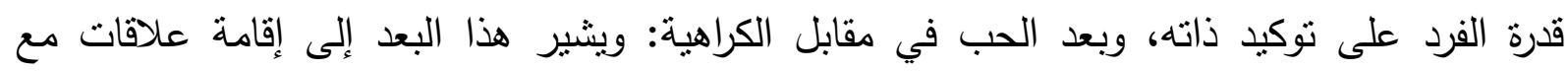

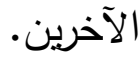

الأساليب والفنيات المستخدمة في تنمية المهارات الاجتماعية: Methods and Technicians Used in the Development of Social Skills:

الملاحظة السلوكية الطبيعية: هو ذللك الإجراء المتبع لملاحظة السلوك المستهدف (كالمهارات

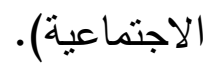
تمثيل الدور ولعب الدور: هو ذلك الإجراء المتبع لملاحظة السلوك المستهدف من خلال مواقف

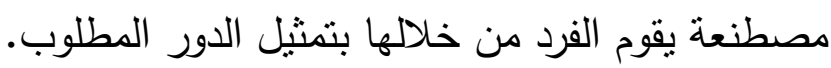
نظريات تفسير المهارات الاجتماعية:

بعتبر سكنر أحد رواد المدرسة السلوكية بل أثنهرهم حيث أعتمد على المنهج الوصفي الوضعي

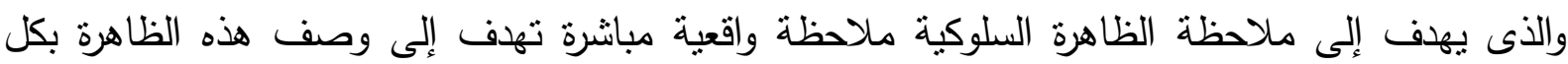

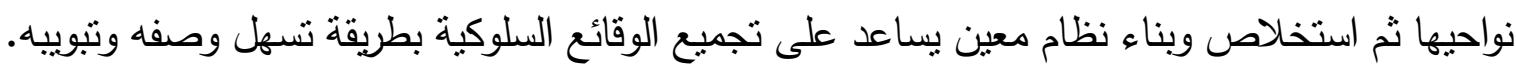

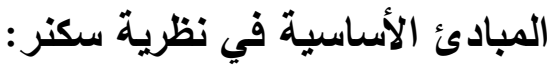

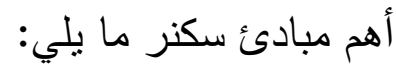

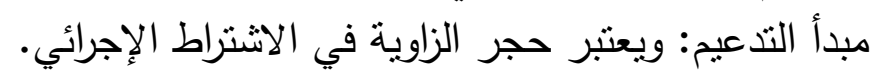

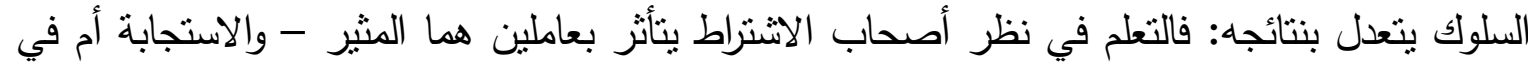

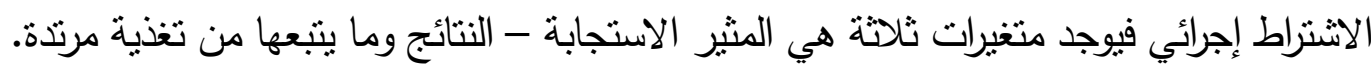
السلوك نشاط ويؤدي إلى أحداث تغيير في البيئة. الأعداد السابق والدقيق لموقف التعلم (التتظيم). يعتمد سكنر في أحداث التعلم على التغذية المرندة (الرجعية).

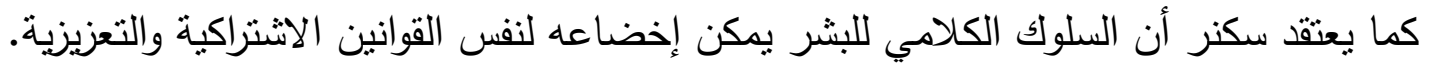

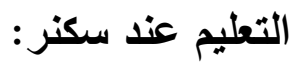

التعلم من وجهة نظر سكنر عبارة عن تغير في احتمال حدوث الاستجابة ويتم هذا التغير بواسطة الانشتراط الإجرائي والاشتراط الإجرائي هو عملية التعلم التي تصبح فئها الاستجابة أكثر احتمالا للحدوث (Jennings \& DiPrete, 2010: 135-159)

المفاهيم والمصطلحات الأساسية في نظرية سكنر:

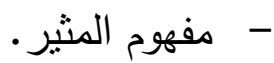
- - مفهوم الاستجابة. - التدعيم أو للتعزيز -

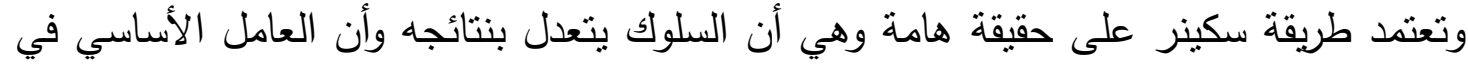

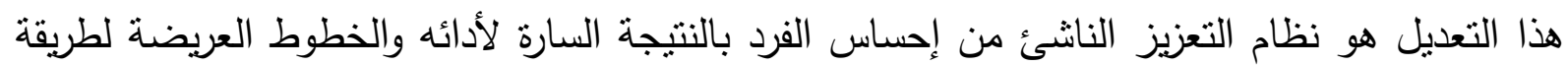
تعديل السلوك هي:

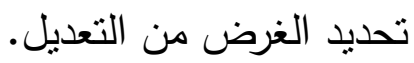


• تحديد السلوك المطلوب تحديدا دقيقا.

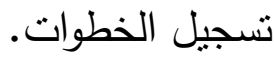

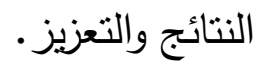

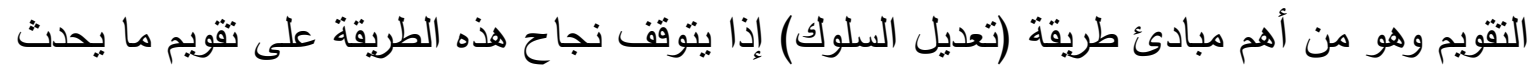

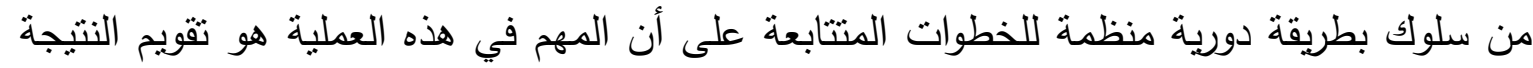
(Jennings \& DiPrete, 2010: 135-159)

$$
\text { النهائية }
$$

الفروض:

ا-توجد فروق ذات دلالة إحصائية فى المهارات الإجتماعية على مقياس المهارات الإجتماعية لدى

$$
\text { أطفال الروضة. }
$$

ץ- لا توجد فروق ذات دلالة إحصائية فى المهارات الإجتماعية على مقياس المهارات الإجتماعية

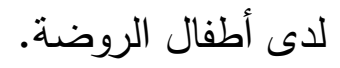

الاجراعات المنهجية

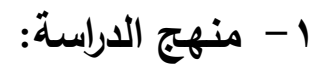

سوف تستخدم الباحثة المنهج شبه التجريبي للتأكد من فاعلية استخدام العداد الصيني في تتمية المهارات الإجتماعية، باستخدام المجموعة الواحدة فى القياسين القبلى والبعدى.

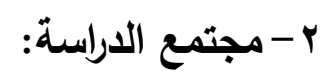

يتكون مجتمع الدراسة من الأطفال في مرحلة رياض الأطفال.

\section{ب- ب- عينة (الاراسة:}

ـ - تكونت العينة من . . 1 طفل وطفلة من مرحلة رياض الأطفال فى المستوى الأول والثانى من

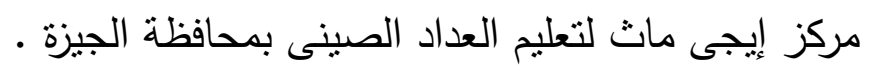

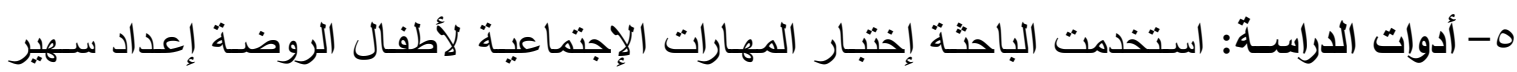

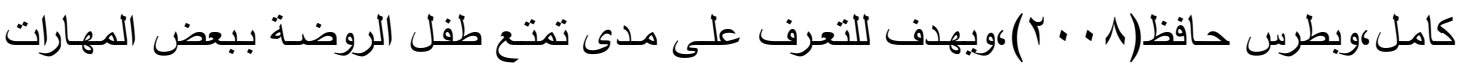

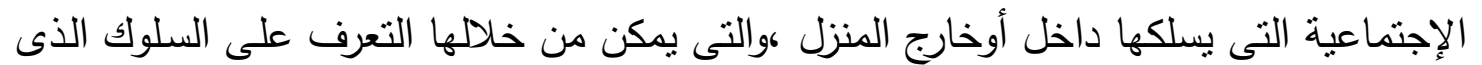
يسلكه مع من فى منل سنه أومع من هم أكبر منهم أو أصغر سناء الصنا. تجانس العينة قامـت الباحثـة بايجـاد التجـانس بـين متوسـط درجـات الأطفـال مـن حيـث العمـر الزمنـى باسـتخدام

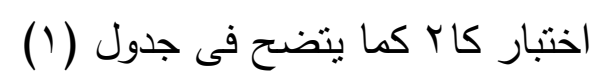




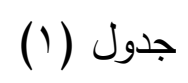

دلالة الفروق بين منوسط رتب درجات الأطفال من حيث العمر الزمنى

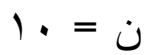

\begin{tabular}{|c|c|c|c|c|c|}
\hline \multicolumn{2}{|c|}{ حدود الدلالة } & \multirow{2}{*}{ درية } & \multirow{2}{*}{ مستوى الدلاية } & \multirow[t]{2}{*}{ كاr } & \multirow[t]{2}{*}{ المتغيرات } \\
\hline ., , & $\cdot, \cdot 1$ & & & & \\
\hline 9,0 & r & $\varepsilon$ & غير دالة & $1, r$ & العمر الزمنح) \\
\hline
\end{tabular}

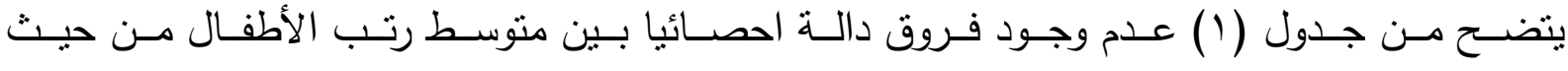
العمر الزمنى مما يشير الى تجني تجانس هؤلاء الأطفال.

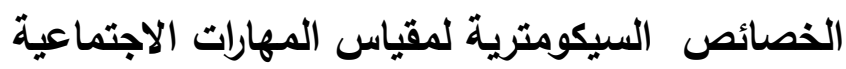

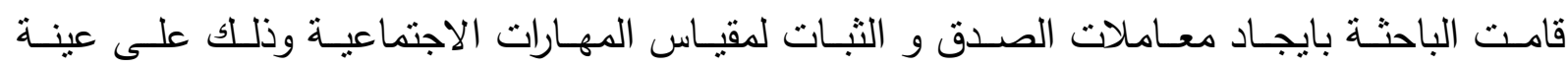
قوامها ... 1 طفل. اولا معاملات الصدق مانق

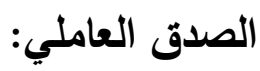

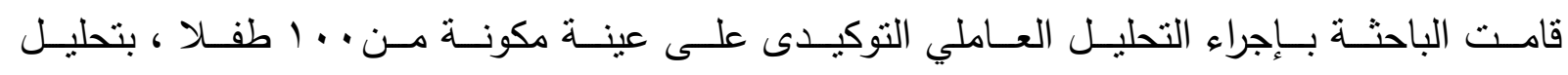

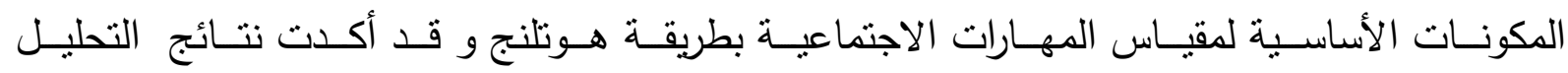

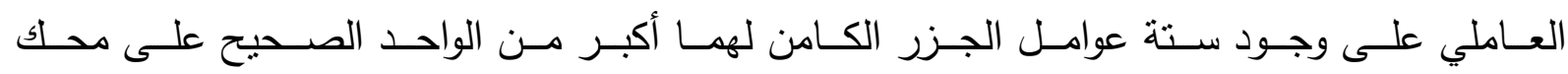

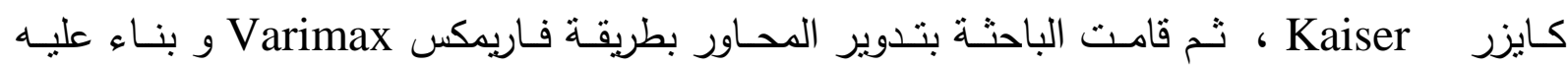

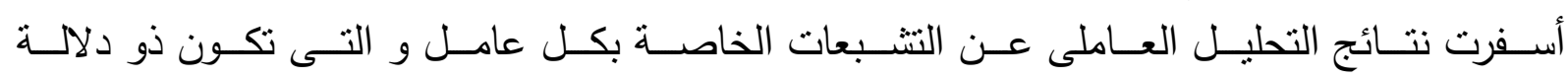

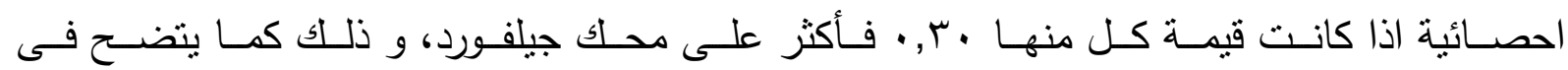

جدول(r) ( جصن ) 
جدول (r)

نتائج التحليل العاملي لمقياس المهارات الاجتماعية

بعد تذوير المحاور

\begin{tabular}{|c|c|c|c|c|c|c|c|c|c|c|c|}
\hline \multicolumn{2}{|c|}{ التعامل ميع البيئة } & \multicolumn{2}{|c|}{ التعبير الانفعالى } & \multicolumn{2}{|c|}{ السلؤك الاجتماعى } & \multicolumn{2}{|c|}{ المشاركةة } & \multicolumn{2}{|c|}{ التفاعل الاجتماعى } & \multicolumn{2}{|c|}{ التواصل مع الاخرين } \\
\hline التئبعات & البنود ا ل البن & التثشبعات & 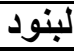 & التشبعات & البنود & التشبعات & البنود & التشبعات & البنود ال البنود & التثبعات & البنود إل البنود \\
\hline$\overline{c, \mathrm{rV}}$ & 7 & 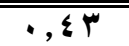 & 0 & $\overline{., \leqslant 9}$ & $\bar{\varepsilon}$ &., $0 \leqslant$ & $\bar{\mu}$ & $\overline{., 01}$ & $\bar{Y}$ &., 70 & $T$ \\
\hline$\cdot, \mathrm{rV}$ & Tr & $\cdot, \varepsilon$ & 11 & 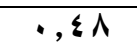 & 1. &., $0 Y$ & 9 &., $0 \mathrm{~V}$ & $\Lambda$ &., 70 & $\mathrm{v}$ \\
\hline$\cdot, r \xi$ & 11 & 纹 & IV & $\cdot, \varepsilon \wedge$ & 17 &., $0 \mathrm{~T}$ & 10 &., $0 \mathrm{~V}$ & $1 \varepsilon$ & $\cdot, 7 \leqslant$ & IT \\
\hline$\cdot, r \varepsilon$ & $Y \leqslant$ & 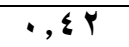 & $\overline{Y T}$ & $\cdot, \xi \mathrm{V}$ & YY &., $0 Y$ & YI &., $0 \mathrm{~V}$ & $r$. & (4 & 19 \\
\hline 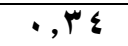 & r. & $\cdot, \leqslant Y$ & rq & $\cdot, \xi \mathrm{V}$ & $r \wedge$ & .,OY & YV & $\cdot, \mathrm{OV}$ & Y4 & (ז & ro \\
\hline • & rq & 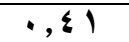 & ro & $\cdot, \leqslant \uparrow$ & $r \varepsilon$ &., 01 & Tr &., 07 & TY & . & ו \\
\hline$\cdot, \mu 1$ & $\varepsilon r$ & $\cdot, \leqslant 1$ & \& & $\cdot, \leqslant 0$ & « &., 01 & rq &., 04 & $\mu \wedge$ & וד & TV \\
\hline . & $\leqslant \Lambda$ & 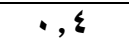 & $\varepsilon v$ & $\cdot, \leqslant 0$ & $\leqslant 7$ &., 0 & $\leqslant 0$ &., 00 & $\varepsilon \varepsilon$ &., 7 & $\varepsilon r$ \\
\hline$\cdot, \mu$ & $0 \leqslant$ & $\cdot, \xi$ & Or & $\cdot, \leqslant \leqslant$ & OY & $\cdot, \leqslant 99$ & 01 &., 00 & 0. &., 09 & $\leqslant 9$ \\
\hline$\cdot, \mu$ & 7. & $\cdot, \varepsilon$ & 89 & ., \& ए & 01 & $\cdot, 49$ & OV &., $0 \leqslant$ & 04 & $\cdot, 01$ & 00 \\
\hline \multicolumn{2}{|c|}{$1, \leqslant 0$} & \multicolumn{2}{|c|}{1,99} & \multicolumn{2}{|c|}{$Y, 0 \leqslant$} & \multicolumn{2}{|c|}{$\overline{Y, T \leqslant}$} & \multicolumn{2}{|c|}{$\overline{Y, V .}$} & $\overline{r, \Lambda 1}$ & الكزن \\
\hline
\end{tabular}

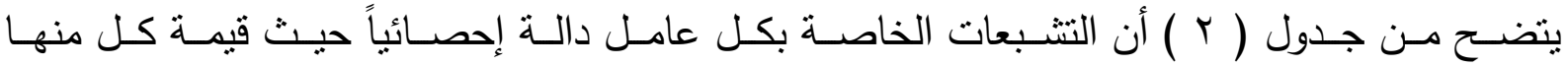

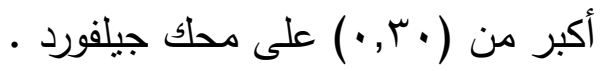

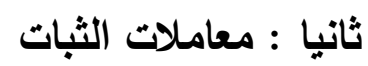
معامل الثبات ( الفا) بطريقة كرونباخ قامـت الباحثنة بايجـاد معـاملات الثبـات لمقيـاس المهـارات الاجتماعيـة باسـتخدام معامـل الفـا بطريقـة

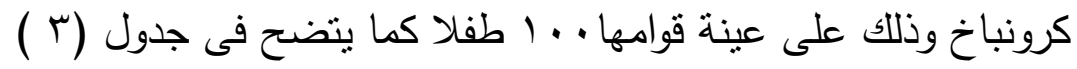

\section{جدول (r )}

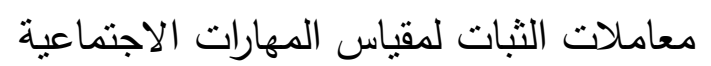

\begin{tabular}{|c|c|}
\hline معامل الثُبات & المتغيرات \\
\hline$\cdot, \wedge \mathrm{T}$ & التو اصل مع الاخرين \\
\hline$\cdot, \wedge \leqslant$ & التفاعل الاجتماعى \\
\hline$\cdot, \wedge \wedge$ & المشاركة \\
\hline$\cdot, \wedge 1$ & السلوك الاجتماعى \\
\hline$\cdot, \wedge \mathrm{T}$ & التعبير الانفعالي \\
\hline$\cdot, \wedge \mathrm{V}$ & التصامل مع البيئة المدرسية \\
\hline$\cdot, \wedge 4$ & اللارجة الكلية \\
\hline
\end{tabular}

يتضح من جدول ( r ) ان قيم معاملات الثبات مرتفعة مما يدل على ثبات الأختبار 
:تتائج البحث :

فرض البحث:

لا توجد فروق ذات دلاله احصائية فى ابعاد المهارات الاجتماعية على كل من (التواصل مع

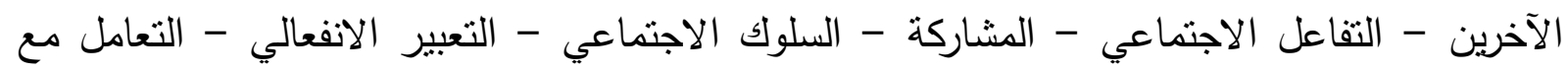
البيئة الأسرية) لدى أطفال الروضة.

للتحقق من صحة ذللك الفرض استخدمت الباحثة اختبار كولموجروف سمر نوف للعينة الواحدة

فne-Sample Kolmogorov-Smirnov Test

فى جدول (ع )

جدول ( ) (c)

المهارات الاجتماعية لدى أطفال الروضة

1. $=\dot{0}$

\begin{tabular}{|c|c|c|c|c|c|c|}
\hline \multirow[t]{2}{*}{ الالالة } & \multirow[t]{2}{*}{$\overline{\mathbf{Z}}$} & \multicolumn{3}{|c|}{ الفروق الاكثر تطرفا } & \multirow[t]{2}{*}{ المتوسط } & \multirow[t]{2}{*}{ المتغيرات } \\
\hline & & السالبة & الموجبة & المطلةة & & \\
\hline دالة عند مستوى I •, • & $\cdot, \leqslant 7$ & $\cdot,\{7)$ & q & $\cdot, \leq 71$ & $Y_{1,7}$ & التواصل مع الآخرين \\
\hline دالة عند مستوى I ·, • & • ( & $\cdot, r \leq$ & • (צחי., & • & (r,o & التفاعل الاجتماعي \\
\hline دالة عند مستوى I ·, ·. & $\cdot, \leqslant \leqslant$ & $\cdot, \leqslant \leqslant 0$ & . & $\cdot, \leqslant \leqslant 0$ & ro,r & المشاركة \\
\hline دالة عند مستوى I +, . & $\cdot, r q$ & $\cdot, r T \cdot$ & $\cdot, Y I \leqslant$ & $\cdot, r \tau$. & 19,1 & السلوك الاجتماعي \\
\hline دالة عند مستوى I ·, . & $\cdot, Y Y$ & $\cdot, 1 T \leq$ & $\cdot, Y Y V$ & $\cdot, Y Y V$ & $17, r$ & التعبير الانفعالي \\
\hline دالة عند مستوى I . , . & $\cdot$, Or & $\cdot, 0 Y \leq$ & • &., $0 Y \varepsilon$ & $r r, q$ & التعامل مع البئة \\
\hline
\end{tabular}

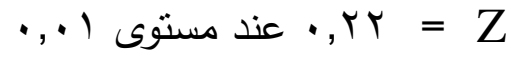

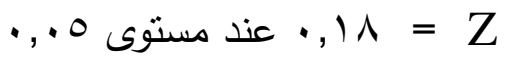

يتضح من جدول (ع) وجود فروق ذات دلاله احصائية عند مستوى ا ب,., فى ابعاد المهارات الاجتماعية على كل من (التواصل مع الآخرين - التفاعل الاجتماعي - المشاركة - السلوك الاجتماعي - التعبير الانفعالي - التعامل مع البيئة الأسرية) على مقياس المهارات الاجتماعية لدى أطفال الروضة الإنية فى اتجاه المشاركة .

ويوضح شكل (1) المهارات الاجتماعية على كل من (التواصل مع الآخرين - التفاعل الاجتماعي - المشاركة - السلوك الاجتماعي - التعبير الانفعالي - التعامل مع البيئة الأسربة) على مقياس المهارات الاجتماعية لدى أطفال الروضة 


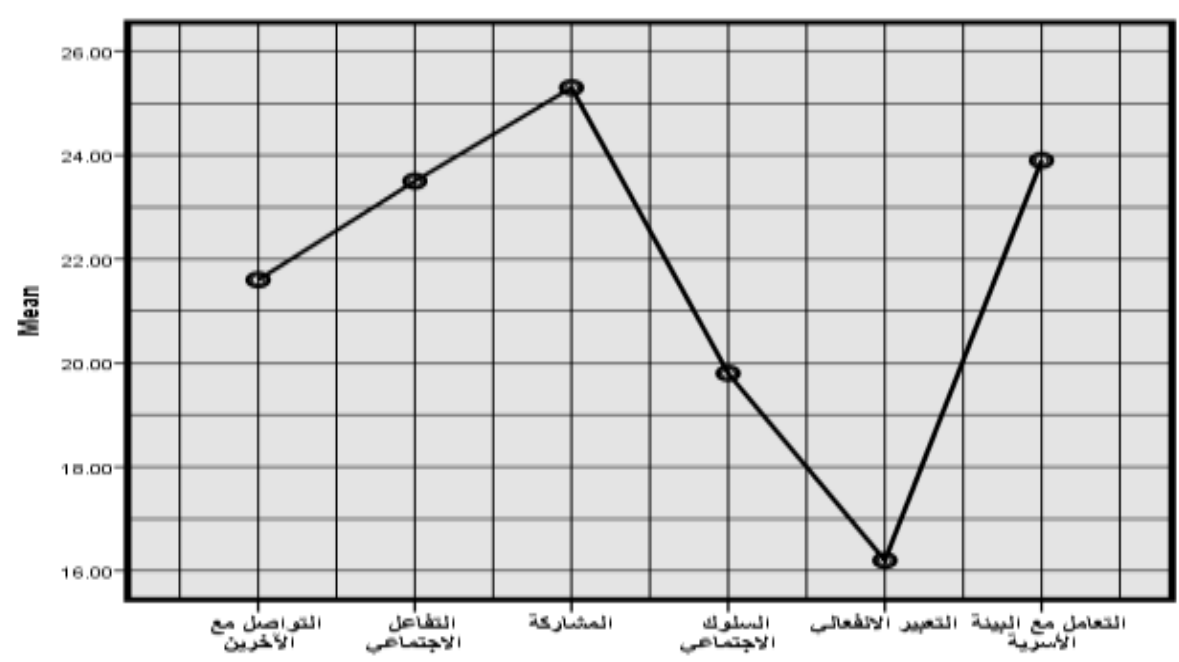

شكل (1)

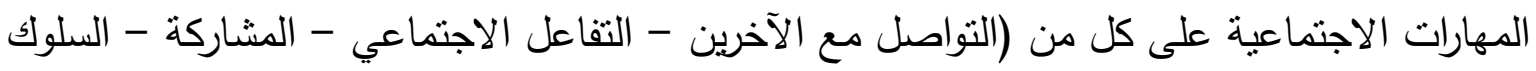

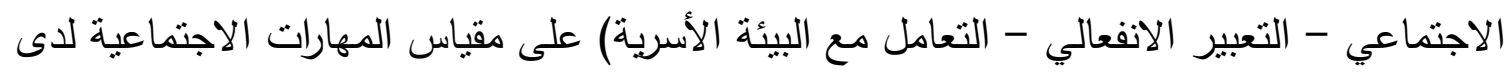

$$
\text { أطفال الروضة الئة الانة }
$$

تفسير النتائج:

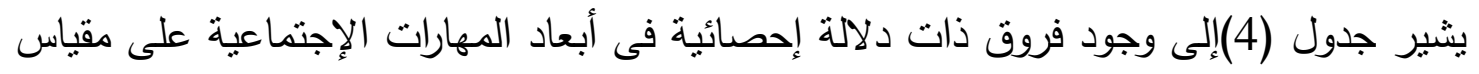

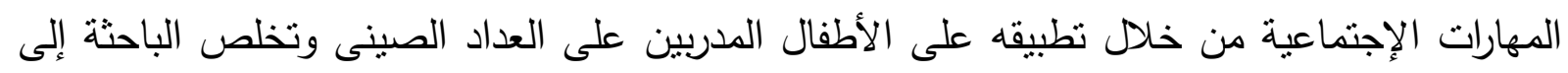

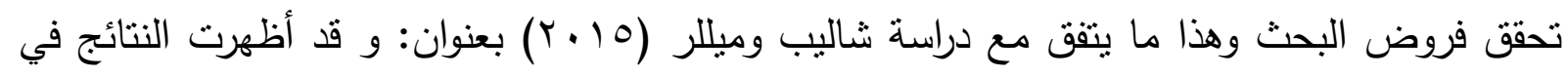

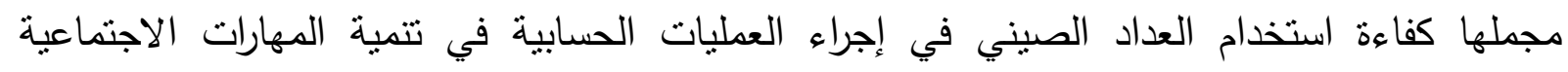

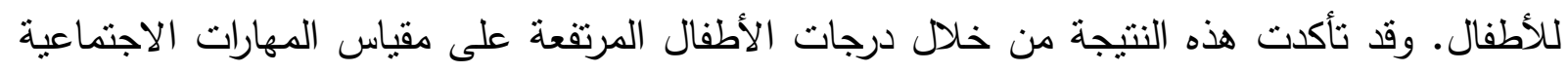

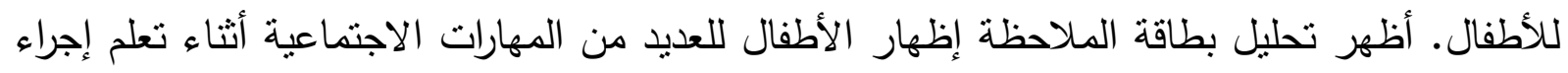

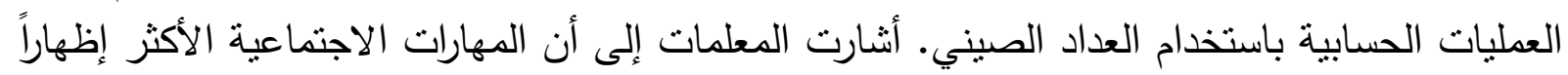

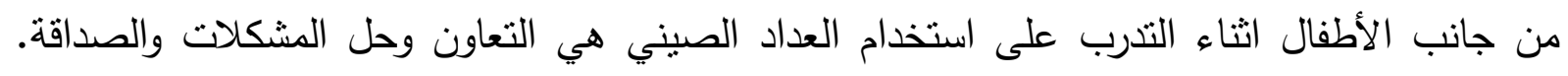

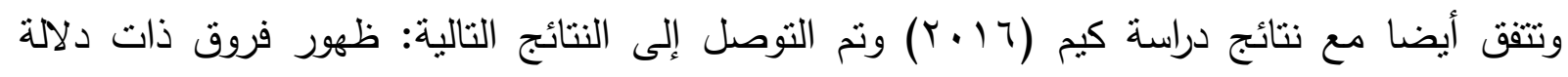

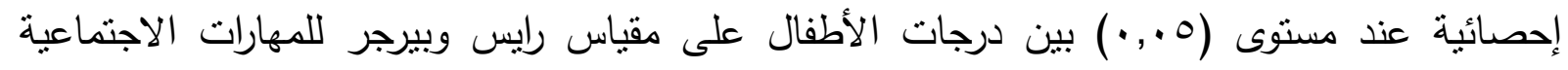

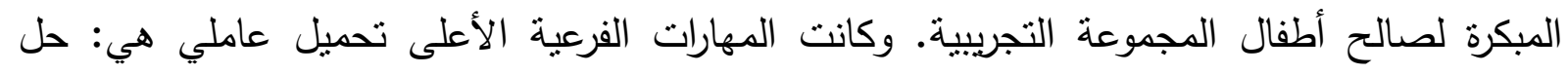

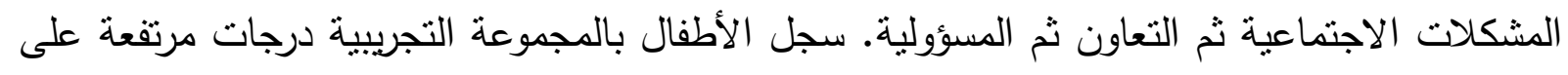
اختبار العمليات الحسابية عبر العداد الصيني.

توصيات الاراسة:

ضرورة تتمية الوعى بالعداد الصينى وأهميته لمرحلة الطفولة المبكرة. ضرورة استخدام العداد الصينى في تعليم الأطفال.

البحوث المقترحة:

دراسة حالة على التدريب باستخدام الأباكس فى مصر .

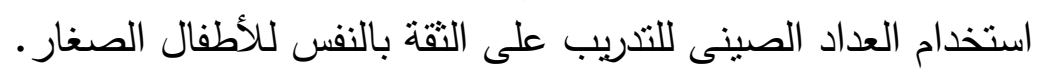

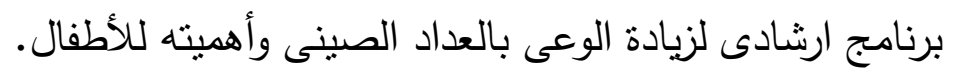




\section{المراجع:

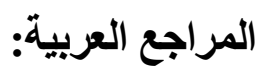

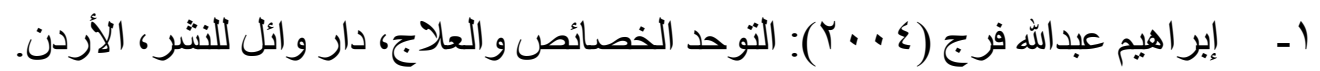

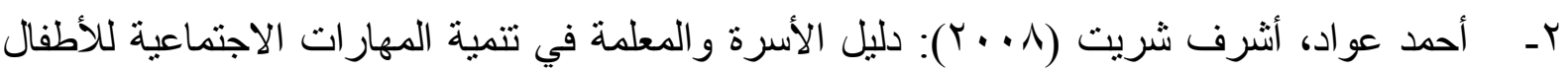
ذوي الإعاقة البصرية، مؤسسة حورس، الإسكندرية.

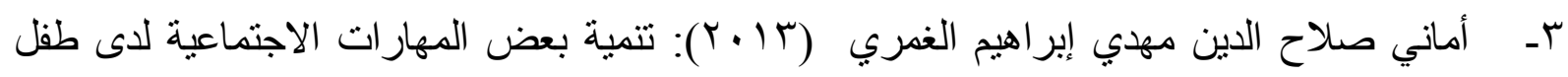
الروضة الإنطو ائي من خلال الأنشطة المتكاملة، ماجستير، معهد الدراسات التربوية، جامعة القاهرة.

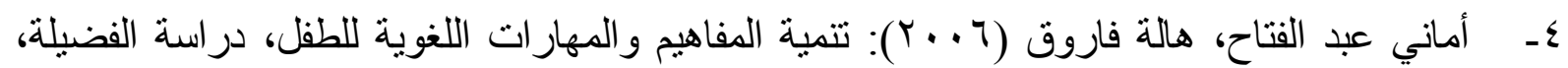

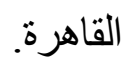

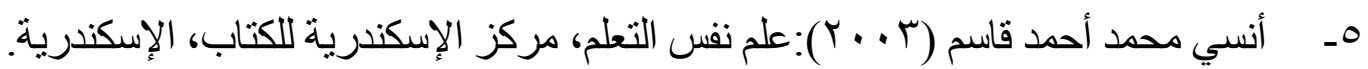

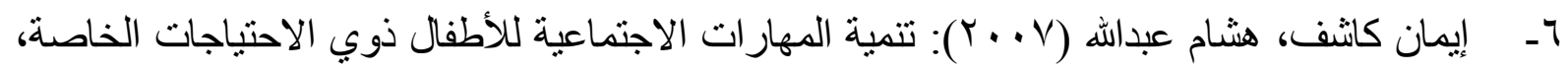

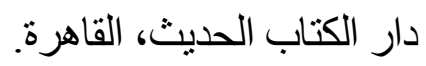

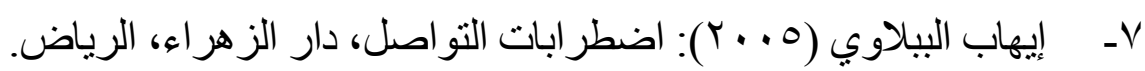

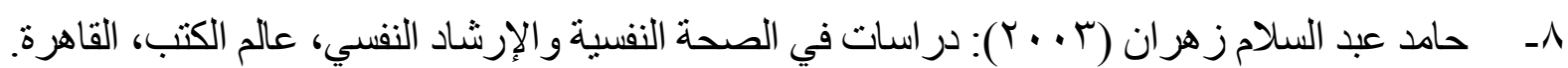

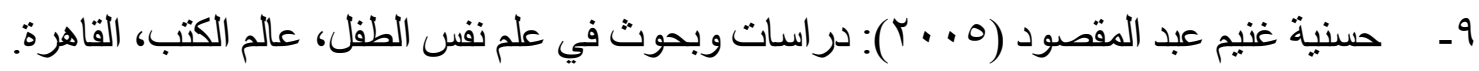

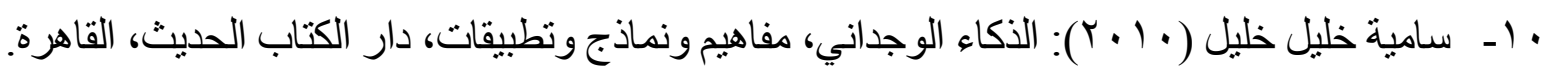

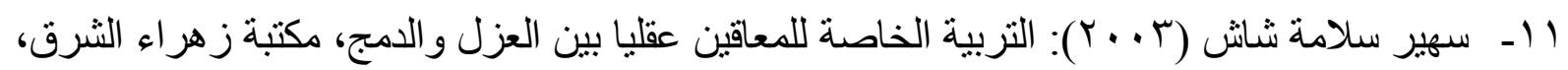
عمان. (1) - n

r ا - سهير كامل (r . - r): سيكولوجية الثخصية، مركز الإسكندرية للكتاب بالإسكندرية.

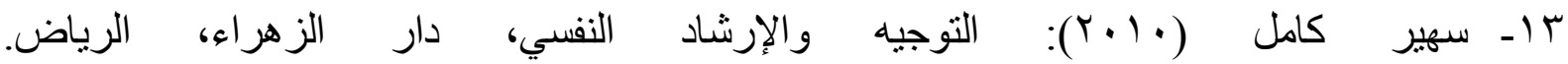
سليمان عبد الواحد( • • ب) :المهارات الحياتية ضرورة حتمية فى عصر المعلوماتية ،أبترالك،القاهرة.

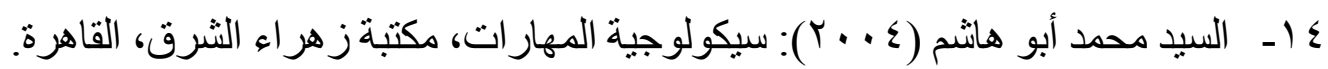

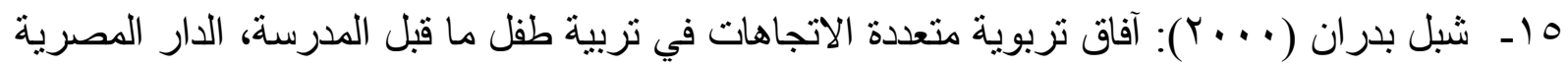
اللبنانية، القاهرة.

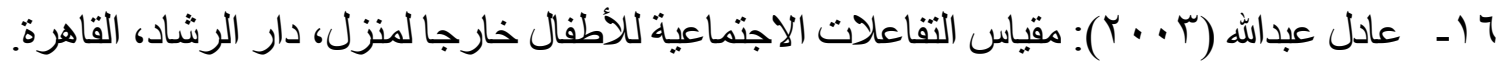

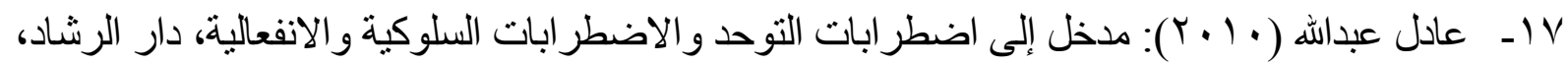

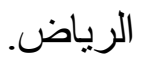

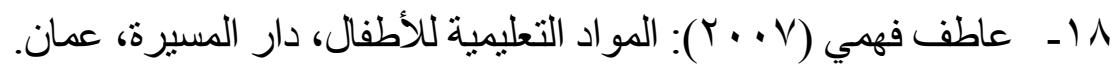




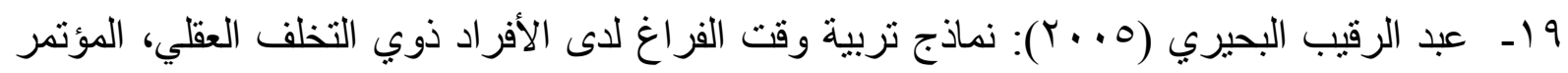

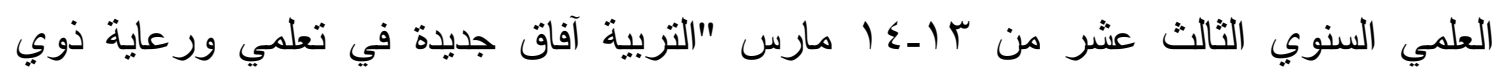
الاحتياجات الخاصة ـ المعاقون و المو هوبون في الوطن العربي، كلية التربية، جامعة حلو ان.

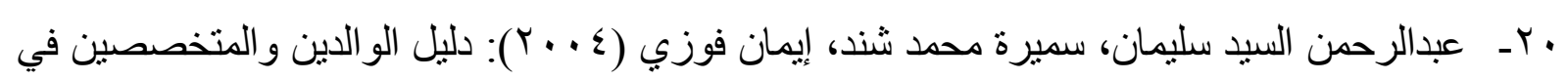
التعامل مع الطفل التوحدي، دار زهر اء الثرق، القاهرة.

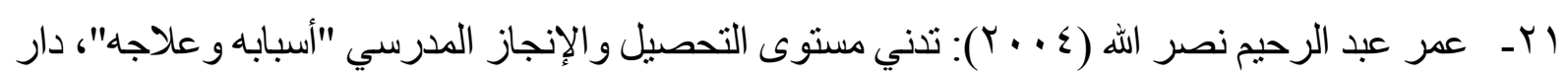
وائل للنشر، الأردن.

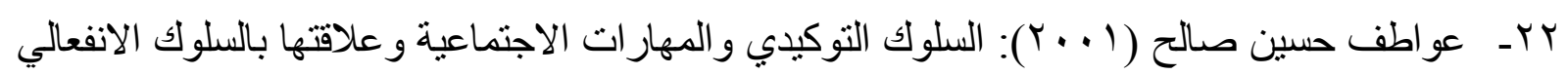

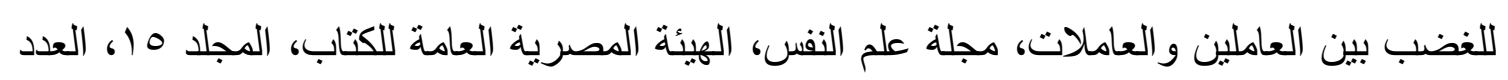
. OV

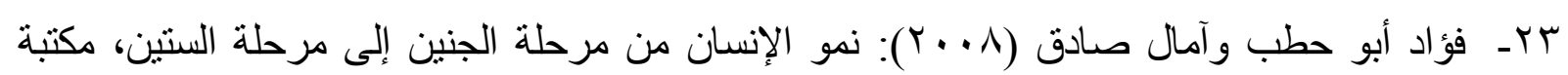
الأنجلو المصرية، القاهرة.

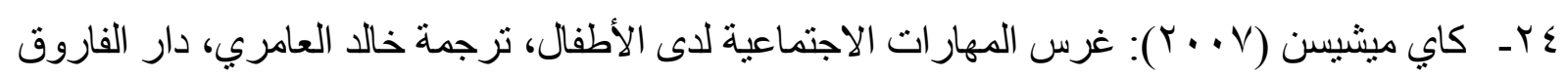
لملاستثمار ات الثقافية، الجيزة.

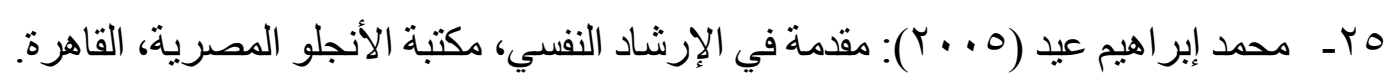

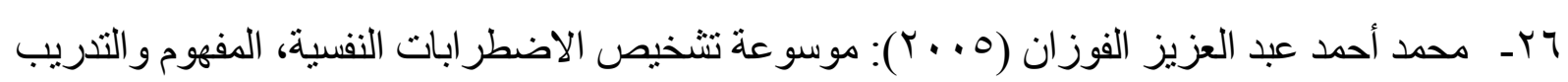

$$
\text { (مرشد إلى الو الدين)، عالم الكتب، القاهرة. }
$$

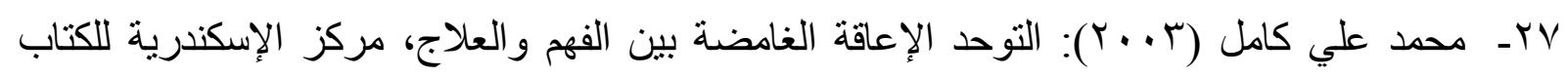
الإسكندرية.

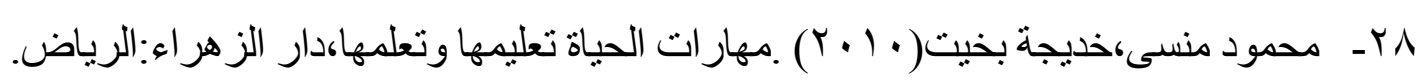

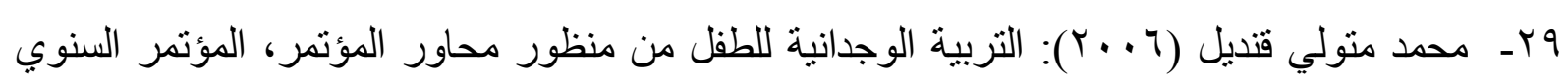

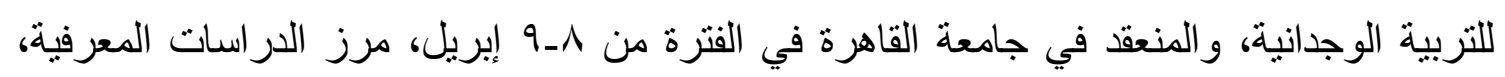
القاهرة.

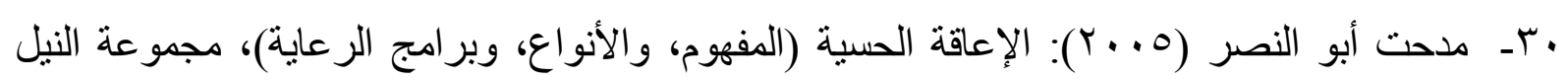
العربية، القاهرة.

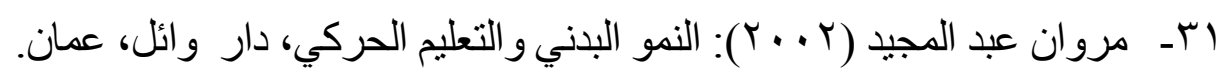

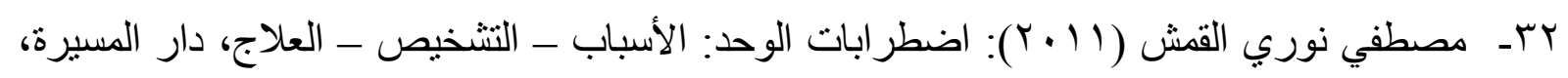




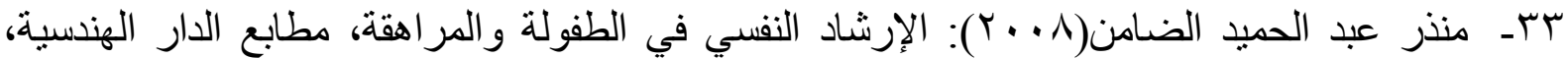

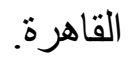

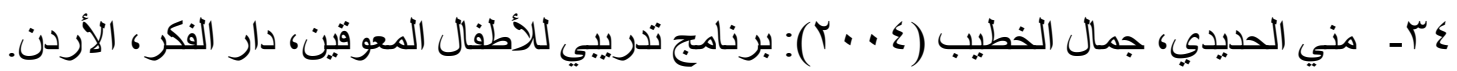

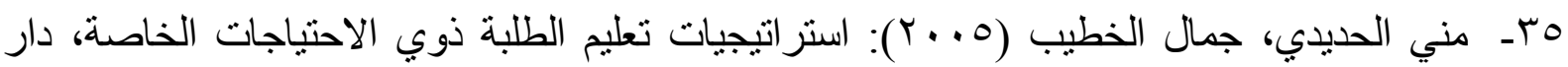

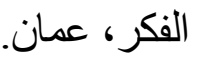

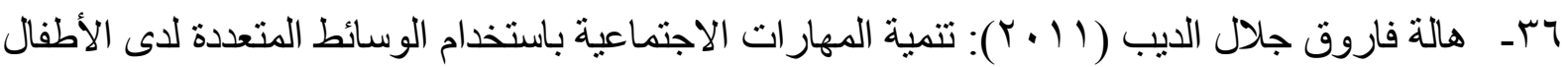
المعاقين عقلياً، مؤسسة حورس الدولية، القاهرة.

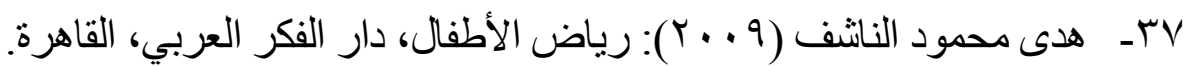

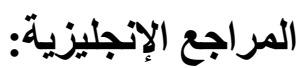

- Altiparmak, K. (2016). The Teachers Views On Abacus Training In Social Skills Development For Children. International Journal of Research in Education and Science (IJRES), 2(1), 172-178.

- Barker A. (2016) Designing Accessible Software for the Electronic Abacus. Proceedings of the 16th International Workshop on Database and Expert Systems Applications (DEXA'05).

- Bridjet, Giles (2005): Developmental Psychology Grang Books, Kent, USA.

- Califano, A. (2015). The Use of Abacus in Children's Training on Social Skills, Journal of Educational Psychology; 1 (4).

- Chalip, K., \& Miller, K. (2015). The Development of Social Skills: The Case of Abacus Training in Taiwan, American Journal of Education; 94 (4).

- Chen, K (2006): Social Skills intervention students with emotional/Behavioral disorders, Aliteratue review from American perspective Educational Research \& Reviews.

- Cheng-Husien, Wu (2007): Social Skill intervention improving peer interaction in child who is an Asian, M.A., Dissertation, West Virginia University, United States. 
- Chung, K. (2016). "Young children's acquisition of mathematical knowledge and mathematics education in kindergarten, $\mathrm{PhD}$ Thesis, Iowa State University: 3.

Craig, A \& Kaiser, B. (2000): Improving the social communication skills of at risk preschool children in play context, Topics in Early Childhood Special Education, Vol, 22, No(1), pp 1-13.

- Fan Kaihui, Dai Lanyu and Liu Lizhu (2017). Analysis of the Effect of Learning of Abacus Mental Arithmetic on Primary Students' Memory Span, copy from International Chinese Mental and Physical Medicine, the 1st periodical, page 24 .

- Frank, M. C., \& Barner, D. (2015). Representing exact number visually using mental abacus. Journal of Experimental Psychology: General, 141, 134-149. doi:10.1037/a0024427

- Gresham, F.M. \& Van, M.B. \& Cook, C. (2006): Social skills training for teaching replacement behaviors: Remediating Acquisition Deficits In-At Risk students, Behavioral Disorders, Vol. 31, N(4), pp 363-377.

- Huang, J.; Du, F.; Yao, Y.; Wan, Q.; Wang, X., \& Chen, F. (2015).Numerical magnitude processing in abacus-trained children with superior mathematical ability: an EEG study, Journal of Zhejiang University-SCIENCE; 16 (8): 661-671.

- Hurlock, E. (2001): Developmental Psychology, A. Life Span Approach, Hill Publishing, Newbelhi.

- Hjalmarson, M.A. \& Suh, J.M. (2016). "Developing Mathematical Pedagogical Knowledge by Evaluating Instructional Materials in Early Childhood", Mathematics Teacher Education, Association of Mathematics Education; 5 (2): 102.

- Hjalmarson, M.A. \& Suh, J.M. (2016). "Developing Mathematical Pedagogical Knowledge by Evaluating Instructional Materials in Early 
Childhood", Mathematics Teacher Education, Association of Mathematics Education; 5 (2): 102.

- Jennings, Jennifer L.; DiPrete, Thomas A. (2010). Teacher Effects on Social and Behavioral Skills in Early Elementary Schoo. Sociology of Education, v83 n2 p 135-159.

- Kazdin, A.E. (2008): Evidence-based treatment and practice: New Opportunities to bridge clinical research can practice, enhance the knowledge base, and improve patient care. American Psychologist, 63, 146159.

- Kim, S. (2016). Social Skills Development of Young Children: Is the Abacus Use Affects These Skills?, PhD Thesis, Columbia University.

- Kolbert, K.; Tauntom, P (2014). Ken Robinson says schools kill creativity. Ted talks, Retrieved June 14, 2014 from: http://www.ted.com/talks/ken_robinson_says_schools_kill_creativity.html.

- Krampner, J. (2014). Ancient abacus: elegant, accurate, fun to operate. Dollar Sense, 10-11. EBSCOhost Full Display, Item No: 9403117506.

- Lee, M., \& Kato, Y. (2017). A Comparison Study About Math Learning Environment: Case of Abacus, ED333A.

- Li, Y.; Chen, F., \& Huang, W. (2016). Neural Plasticity following Abacus Training in Humans: A Review and Future Directions, Neural Plasticity Volume 2016, Article ID 1213723.

- Merrell, Kenneth (2001): Assessment of childrens social skills, Recent Development best Practice Expceptionality, Vol. 9,N o (1), pp 3-16.

- Nool, N. R. (2015). Effectiveness of an Improvised Abacus in Teaching Addition of integer, International Conference on Education and Management Innovation, Singapore, pp. 307--311.

- Riggio, Y. (2005): Assessment of basic and social Psychology, Vol. 5, No (3), pp 649-660. 
- Segrin C. \& Flora J. (2006). Poor social skills are vulnerability factor in the development of psychosocial problems human communication research, Journal of social behavior and personality, Vol. 36, No (3), pp 489-514.

- Stahl, K. (2008): Characteristics in School Social Skills Programs that increase implementation within the classroom, New York.

- Stigler James and Smith Sheila (2005): The Self Perception of Competence by Chinese Children. University of Chicago Taipi Municipal government Child Development. Vol. 65: (12590-1270).

- Tan, P.; Moody, L.; Bromage, A., \& Richards, C. (2016). Effects of the Abacus for Teaching Mathematics for Young Children on Social Skills, The Asian Conference on Education, Malaysia.

Uttal, D. H.; Scudder, K. V., \& Deloache, J. S. (2016). Manipulatives As Symbols: A New Perspective On The Use Of Concrete Objects To Teach Mathematics, Journal Of Applied Developmental Psychology, 18,37-54.

- Valsamidou, Lina (2012): Students in the Role of Journalists: School News Paper Publications about social Behavior and the Mass Media, Journal of Studies in Education, Vol. 2, pp 2162-2169.

- Vaughn, S., Morris, S. (2003): Social skills interventions for young children with Disabilities, Remedial Special education. Jan/Feb, Vol. 24, No(1), pp 2-14.

- Wohlschl€ager, A. (2013). Mental object rotation and the planning of hand movements. Attention, Perception, \& Psychophysics, 63(4), 709-718. 